Review

\title{
An update on molecular biology and drug resistance mechanisms of multiple myeloma
}

\author{
Pelin Mutlu ${ }^{\mathrm{a}}$, Yağmur Kiraz ${ }^{\mathrm{b}}$, Ufuk Gündüz ${ }^{\mathrm{c}}$, Yusuf Baran ${ }^{\mathrm{b}, \mathrm{d}, *}$ \\ a Middle East Technical University, Central Laboratory, Molecular Biology and Biotechnology RED, Ankara, Turkey \\ b Izmir Institute of Technology, Department of Molecular Biology and Genetics, İmir, Turkey \\ ${ }^{c}$ Middle East Technical University, Department of Biological Sciences, Ankara, Turkey \\ d Abdullah Gul University, Faculty of Life and Natural Sciences, Department of Molecular Biology and Genetics, Kayseri, Turkey
}

\section{Contents}

1. Introduction

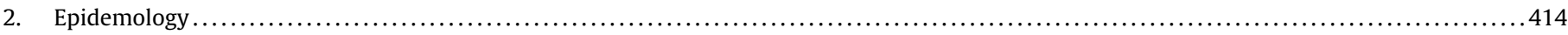

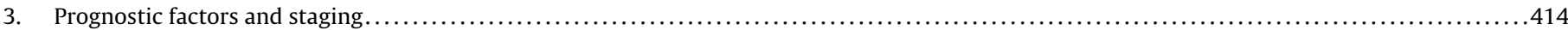

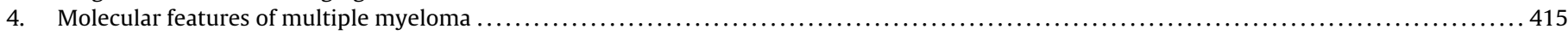

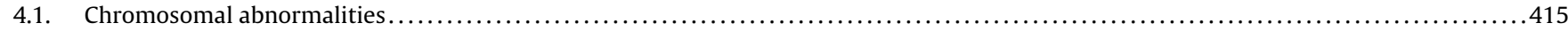

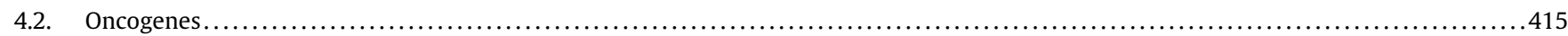

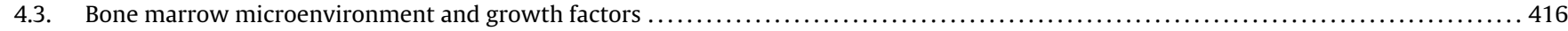

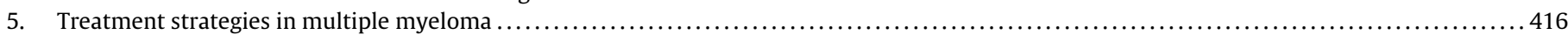

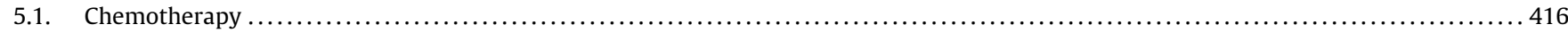

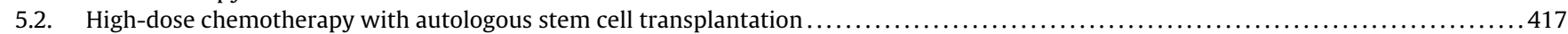

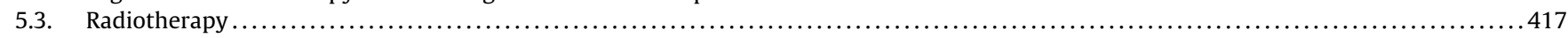

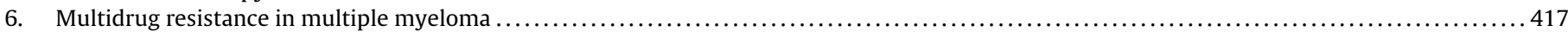

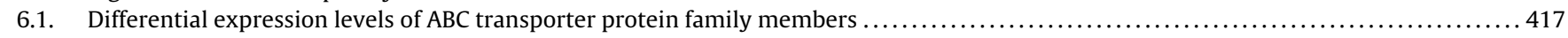

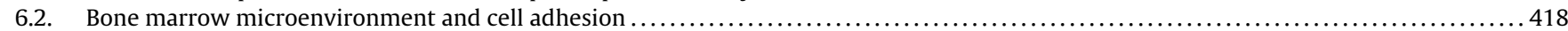

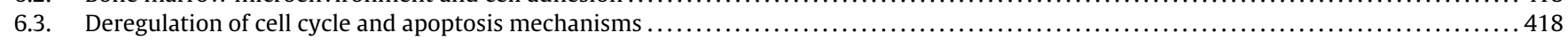

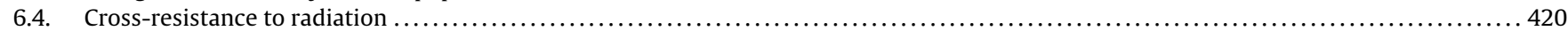

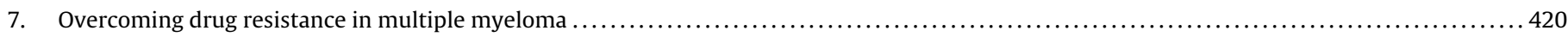

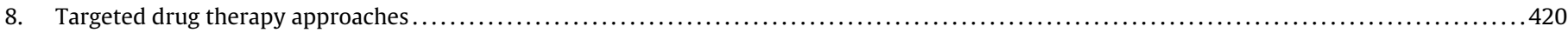

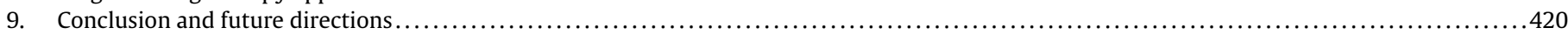

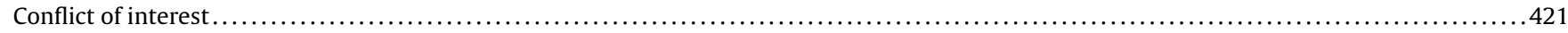

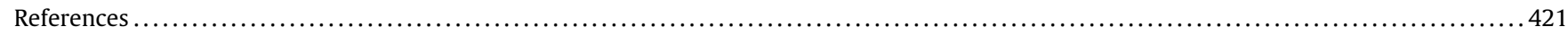

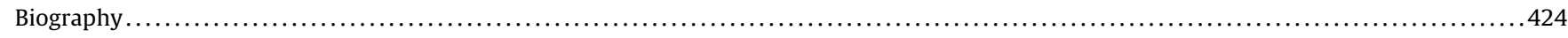

\section{A R T I C L E I N F O}

\section{Article history:}

Received 31 August 2014

Received in revised form 11 June 2015

Accepted 7 July 2015

\section{Keywords:}

Multiple myeloma

Molecular aspects

Drug resistance

Targeted drug delivery

\begin{abstract}
A B S T R A C T
Multiple myeloma (MM), a neoplasm of plasma cells, is the second most common hematological malignancy. Incidance rates increase after age 40. MM is most commonly seen in men and African-American population. There are several factors to this, such as obesity, environmental factors, family history, genetic factors and monoclonal gammopathies of undetermined significance (MGUS) that have been implicated as potentially etiologic. Development of MM involves a series of complex molecular events, including chromosomal abnormalities, oncogene activation and growth factor dysregulation. Chemotherapy is the most commonly used treatment strategy in MM. However, MM is a difficult disease to treat because of its marked resistance to chemotherapy. MM has been shown to be commonly multidrug resistance (MDR)-negative at diagnosis and associated with a high incidence of MDR expression at relapse. This review deals with the molecular aspects of $\mathrm{MM}$, drug resistance mechanisms during treatment and also possible new applications for overcoming drug resistance.
\end{abstract}

(c) 2015 Elsevier Ireland Ltd. All rights reserved.

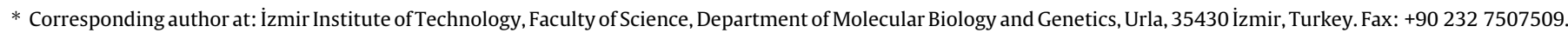

E-mail address: ybaran@gmail.com (Y. Baran).
} 


\section{Introduction}

Multiple myeloma (MM) fits in the group of plasma cell disorders characterized by neoplastic proliferation of plasma cells which produce and secrete monoclonal antibodies, usually IgG or IgA isotypes (MacLennan, 1991). The monoclonal protein secreted by MM plasma cells is immunoglobulin or a component of immunoglobulin which is called M-protein or paraprotein. Due to the mutations in the genes that are responsible for immunoglobulin production in myeloma cells, the normal antibody function of the immunoglobulin is lost. Excess M-protein accumulates in the bloodstream and/or in the urine of the MM patients (Botallie and Harousseau, 1997; Kyle and Rajkumar, 2008; Palunbo and Anderson, 2011).

Plasma cells are the end-stage effector cells of the B-lymphocyte lineage that produce and secrete antigen-specific antibodies (MacLennan, 1991). In contrast with the distribution of normal plasma cells, MM plasma cells localize specifically within the bone marrow, produce $\mathrm{M}$-protein and a number of cytokines such as interleukin (IL)- $1 \beta$, tumor necrosis factor (TNF)- $\beta$ and monocyte-macrophage colony stimulating factor activating stromal and accessory cells and also have osteoclast activating factor (OAF) activity leading to the typical punched out osteolytic lesions (Cozzolino et al., 1989; Mundy et al., 1974; Nakamura et al., 1989; Ross Garrett et al., 1987).

Bone marrow microenvironment of MM is well organized in terms of adhesive properties and production of the cytokines for growth and differentiation of plasma cells. A number of cytokines, including IL-1 $\beta$ and M-CSGF, are released from plasma cells and activate bone marrow stromal cells to produce IL-6, which stimulates the proliferation of plasma cells (Caligaris-Cappio et al., 1992; Jernberg et al., 1991; Kishimoto, 1989; Klein et al., 1989; Nilsson et al., 1990; Nordan and Potter, 1986; Zhang et al., 1989). Most recently, IL-6 has also been shown to enhance survival of MM cells by inhibition of apoptosis triggered by corticosteroids, serum starvation and anti-Fas (Hulkkonen et al., 2001; Humphries et al., 2001; Sfrent-Cornateanu et al., 2006). Elevated IL-6 serum levels are correlated with poor prognosis, higher tumor cell mass and also osteoclast activation in MM (DeMichele et al., 2003; Jerrard-Dunne et al., 2003; Jones et al., 2001; Sawczenko et al., 2005; Snoussi et al., 2005).

Multiple myeloma patients usually present with bone destruction, hypercalcemia, renal damage, increased susceptibility to infections and anemia (Kyle and Rajkumar, 2008; Morgan et al., 2002). There are no established risk factors for MM other than gender, age, ethnicity, family history of lymphatohematopoitic cancer (LHC) and monoclonal gammopathy of undetermined significance (MGUS). Annual risk of progression of MGUS to multiple myeloma is approximately $1 \%$ (Ries et al., 2005).

\section{Epidemology}

According to Multiple Myeloma Research Foundation, MM is the second most common blood cancer after non-Hodgkin's lymphoma and represents approximately $1 \%$ of all cancers in white individuals and $2 \%$ of all cancers in black individuals (Multiple Myeloma Research Foundation, 2015).

MM occurs more frequently in men than in women, and its highest incidence has been found in African-American population, being twice as high compared with white population. Incidence rates for most European countries, white Americans and Canadians are similar. The lowest incidence of myeloma has been found among Asian individuals (American Cancer Society, 2005; Parkin et al., 2002; Ries et al., 2005). Blacks may be two times more likely to develop multiple myeloma with respect to whites since they are
Table 1

Durie and Salmon staging system.

\begin{tabular}{ll}
\hline Criteria & $\begin{array}{l}\text { Measured myeloma cell mass } \\
\text { (myeloma cells in billions/m }{ }^{2} \text { ) }\end{array}$ \\
\hline Stage I (low cell mass) & 600 billion \\
All of the following: & \\
- Hemoglobin value $>10 \mathrm{~g} / \mathrm{dl}$ & \\
- Serum calcium value normal or & \\
$<$ - 10.5 mg/dl \\
Bone X-ray, normal bone \\
structure (scale 0 ) or solitary \\
bone plasmacytoma only \\
- Low M-component production \\
rates \\
IgG value $<5.0 \mathrm{~g} / \mathrm{dl}$ \\
IgA value $<3.0 \mathrm{~g} / \mathrm{dl}$ \\
Urine light chain M-component \\
$<4 \mathrm{~g} / 24 \mathrm{~h}$ \\
Stage II (intermediate cell mass) \\
Fitting neither Stage I nor Stage II \\
Stage III (high cell mass) \\
- One or more of the following: \\
- Hemoglobin value $<8.5 \mathrm{~g} / \mathrm{dl}$ \\
- Serum calcium value $>12$ mg/dl \\
- Advanced lytic bone lesions \\
(scale 3 )
\end{tabular}

more likely to have a precursor condition known as MGUS (Cohen et al., 1998; Landgren et al., 2006; Singh et al., 1990).

Increased risk for association between obesity and MM has been reported in a few epidemiologic studies (Blair et al., 2005; Pan et al., 2004). Findings for tobacco use and alcohol consumption do not support a causal association with multiple myeloma (Brown et al., 1992, 1997; Brownson, 1991; Mills et al., 1990; Nieters et al., 2006; Pan et al., 2004; Vlajinac et al., 2003). Although the incidence of MM is higher in males than in females, the studies suggest that hormonal influences do not play a significant etiologic role in MM (Altieri et al., 2004; Fernandez et al., 2003).

\section{Prognostic factors and staging}

Diagnosis of MM is confirmed according to the growth rate of myeloma cells, production rate of monoclonal proteins and various cytokines. In 1975, Durine/Salmon staging system was developed as shown in Table 1 (Durie and Salmon, 1975). This is actually a functional system which serves to evaluate the prognosis using various types of clinical and laboratory tests. Durine/Salmon staging system is used worldwide since it provides the best direct correlation between individual patient clinical features and it differs from anatomic staging systems for solid tumors.

A new staging system was developed by the IMF-sponsored International Myeloma Working Group in 2005. In this staging system, serum $\beta 2$ microglobulin and albumin levels provide a powerful and reproducible three- ekleyelim stage classification (Grepp and Durie et al., 2005). Myeloma can be further classified upon genetic factors using molecular fluorescence in situ hybridization (FISH) and cytogenetic analysis (Zojer et al., 2001). 


\section{Molecular features of multiple myeloma}

Development of MM may proceed via a multistep transformation process which involves a series of molecular events, including chromosomal abnormalities, oncogene activation and growth factor dysregulation as detailed below (Bottura, 1963).

\subsection{Chromosomal abnormalities}

Aneuploidy is one of the common findings in MM. The first prognostically significant classification of MM was based on chromosome ploidy number; as hypodiploid group indicated poor survival, whereas hyperdiploidy is suggested to indicate good prognosis (Smadja et al., 1995). Hyperdiploidy mostly involves chromosomes 3, 5, 7, 9, 11, 15, 19, and 21 (Dao et al., 1994; DeWald et al., 1985; Sawyer et al., 1995) while hypodiploidy commonly affects chromosomes 13, 14, 16, and 22 (Fonseca et al., 2004; Smadja et al., 2001, 1998). In general, hypodiploid karyotypes typically have translocations involving the immunoglobulin heavy chain (IGH) at locus 14q32 (Fonseca et al., 2004; Smadja et al., 2001, 1998). Translocation between chromosomes 11 and $14, \mathrm{t}(11: 14)(\mathrm{q} 13 ; \mathrm{q} 32)$, is the single most common chromosomal abnormality in myeloma and involves $b c l-1$ oncogene. It is found in about $15 \%$ of patients and appears to be associated with a favorable outcome (Bergsagel and Kuehl, 2005; Fonseca et al., 2009, 2002).

The second most common translocation is $\mathrm{t}(4: 14)(\mathrm{p} 16 ; \mathrm{q} 32)$ (Chesi et al., 1998; Santra et al., 2003). This translocation involves Wolf-Hirschhorn syndrome candidate 1 gene (WHSC1) and fibroblast growth factor receptor 3 (FGFR3), which is an oncogenic receptor tyrosine kinase gene (Kuehl and Bergsagel, 2002). The $t(4: 14)$ is also associated with a high prevalence of chromosome 13 monosomy and deletions also has been associated with poor survival (Avet-Loiseau et al., 2007; Fonseca et al., 2003; Gertz et al., 2005; Keats et al., 2003).

The $t(14 ; 16)(q 32 ; q 23)$ translocation is less commonly observed but has significant importance in clinical process. It juxtaposes the IGH (14q32) locus and c-MAF (16q23) locus and is found in approximately $6-7 \%$ of MM cases. This translocation is also associated with poor outcome (Avet-Loiseau et al., 2007; Fonseca et al., 2009).

Secondary chromosomal aberrations are found during tumor progression and four of them are most often reported. Translocations and/or amplifications of the MYC oncogene and Ig locus (8q24) are involved in $45 \%$ of the patients and are known to be late-stage events in tumor progression (Bergsagel and Kuehl, 2001; Gabrea et al., 2008). Aberrations, either complete monosomy or constitute deletion of chromosome 13, and are found in about 50\% of MM patients (Tricot et al., 1995, 1997). Recent studies suggest that prognostic significance of monosomy 13 may be in a close association with the translocation $\mathrm{t}(4: 14)$ (p16; q32) (Fonseca et al., 2009; Keats et al., 2003). Deletion of 17p13 leads to the loss of heterozygosity of TP53 gene, which is a rare late-stage event being reported in 10\% of MM patients (Corradini et al., 1994; Neri et al., 1993). The deletion of $17 q 13$ consistently correlates with a poorer outcome (Fonseca et al., 2009, 2002). Most of the structural aberrations in MM occur in chromosome 1. Deletions generally involve in $1 \mathrm{p}$ whereas amplifications correspond to 1q (Le Baccon et al., 2001; Qazilbash et al., 2007).

\subsection{Oncogenes}

Molecular mechanisms of lymphoid neoplasia can be divided into two categories, including activation of proto-oncogenes by chromosomal translocations or point mutations and tumor suppressor gene inactivation (Gaidano and Dalla Favera, 1992).

Proto-oncogene activation by chromosomal translocations is common in lymphoid neoplasia. Translocation can have one of the two effects. At first, many translocations involve an antigen receptor locus on one partner chromosome and a proto-oncogene on the other. Secondly, translocations may cause the formation of novel fusion transcripts resulting in proto-oncogene activation. Activation of proto-oncogene leads to chimeric proteins displaying novel biochemical properties distinct from those of wild type proteins (Gaidano and Dalla Favera, 1992).

c-myc oncogene encodes a transcriptional factor stimulating Bcell proliferation and repression of $\mathrm{B}$-cell differentiation. These are the important steps in the pathogenesis of human B-cell malignancies. Moreover, $c$-myc was the first oncogene whose involvement was evaluated in MM (Meltzer et al., 1987; Neri et al., 1989; Selvanaygam et al., 1988). It is activated through a translocation that juxtaposes it on chromosome 8 and the immunoglobulin genes on chromosome 2,14 , or 22 . Among them, $t(8 ; 14)(\mathrm{q} 24 ; \mathrm{q} 32)$ is a more frequent one placing $c-m y c$ oncogene under the control of immunoglobulin transcriptional enhancer regions (Gaidano and Dalla Favera, 1992). Alterations in the c-myc locus were reported in some of the studies (Meltzer et al., 1987; Neri et al., 1989; Selvanaygam et al., 1988) but still appear uncommon in MM (Neri et al., 1989; Palumbo et al., 1990; Paquette et al., 1990). Although alterations within the myc appear uncommon, high incidence of rearrangements (16\%) was reported at the Moloney leukemia virus integration-4 (MLVI-4) locus. This molecular lesion is correlated with therapy resistance suggesting its involvement in late-stages of oncogenesis (Palumbo et al., 1990).

The bcl-1 locus was initially identified as the breakpoint site on chromosome 11 of the translocation $t(11 ; 14)(q 13 ; q 32)$, which is detected in $50 \%$ of intermediate lymphocytic lymphomas (Raffeld and Jaffe, 1991). It juxtaposes the immunoglobulin heavy-chain locus on chromosome 14 with sequences from chromosome 11. This rearrangement involves the regulation of cell cycle progression (Raffeld and Jaffe, 1991). However, its incidance appears to be very low, $t(11 ; 14)$ is being the single most common recurring translocation in cytogenetic studies of MM. (DeWald et al., 1985; Nishida et al., 1989; Paquette et al., 1990; Williams et al., 1991).

Translocation $\mathrm{t}(14 ; 18)(\mathrm{q} 32 ; \mathrm{q} 21)$ joins the bcl-2 gene at its $3^{\prime}$ untranslated region to immunoglobulin heavy-chain sequences resulting in $b c l-2$ deregulation, and it is the most frequent chromosomal abnormality in B-cell non-Hodgkin's lymphomas (Lee et al., 1987). Constitutively, high levels of bcl-2 protein prevent programmed cell death (Hokkenberry et al., 1990). Although reports about translocation $\mathrm{t}(14 ; 18)(\mathrm{q} 32 ; \mathrm{q} 21)$ in MM are very rarely seen, there are several studies determining overexpression of bcl-2 protein in MM patients (Durie et al., 1990; Durie, 1992; Hamilton et al., 1991).

Increased levels of p53 mRNA and point mutations in exons 5 and 8 were previously detected in human myeloma cell lines (Palumbo et al., 1989). The incidence of p53 mutations in bone marrow samples of patients with plasma cell dyscrasias ranges between 10 and 20\%, which is generally associated with advanced and aggressive forms of multiple myeloma (Portier et al., 1992).

$R b 1$ gene is expressed in human hematopoietic cells and is associated with the regulation of proliferation and terminal differentiation (Benedict et al., 1990; Tang et al., 1992). Immunohistochemical analysis demonstrated that, this protein is completely absent in $17 \%$ of multiple myeloma patients (Palumbo et al., 1989). On the other hand, activating mutations of $N-R A S$ and $K-R A S$ are each present in about 15\% of MM cases (Korde et al., 2011).

Even though many data have been accumulated on the molecular lesions involved in myeloma pathogenesis, none of the oncogenes and tumor suppressor genes that are examined was changed in the vast majority of MM patients in contrast to other neoplasms where a specific lesion is present in almost all cases. 


\subsection{Bone marrow microenvironment and growth factors}

The microenvironment of bone marrow has an important role in the evolution of myeloma. Multiple myeloma develops in bone marrow within close interaction with stromal cells such as myeloid cells, monocytes, fibroblasts, osteoblasts, osteoclasts and vascular endothelial cells. Early in the disease, tumor cells are stromal dependent. However, as the disease progresses and becomes more aggressive, the myeloma cells become stromal independent (Kuehl and Bergsagel, 2002).

The interaction between bone marrow stromal cells and myeloma cells can be either directly via sydecan 1 and very late antigen 4 (VLA-4) or indirectly by the secretion of soluble cytokines, adhesion molecules, and growth factors. This communication is involved in pathogenesis of osteolytic lesions in the disease since these mechanisms involve osteoclast activation and osteoblast inactivation (Barlogie et al., 2005; Hideshima et al., 2004).

Bone destruction and development of the osteolytic lesions are frequently seen in MM (Bataille et al., 1989). Receptor activator of $\mathrm{NF}-\kappa \mathrm{B}$ (RANK) is a transmembrane signaling receptor expressed by osteoclast cells. Binding of MM cells to BMSC results in increased receptor activator of NF- $\kappa \mathrm{B}$ ligand (RANKL) expression. This causes an increase in osteoclast activity through the binding of RANKL to its receptor, which is located on osteoclast precursor cells (Erlich and Roodman, 2005). There are also several other factors implicated in osteoclast activation, such as macrophage inflammatory protein-1a (MIP-1a), interleukin-3 (IL-3) and interleukin-6 (IL-6) (Roodman, 2009).

Suppression of osteoblast activity is responsible for bone destructive process and progression of myeloma. DKK1, which is responsible for suppression of osteoblast activity in MM, is significantly overexpressed in MM patients with lytic bone lesions, (Tian et al., 2003; Yaccoby et al., 2007).

IL-6 is a crucial cytokine and growth factor for plasmablastic cells (Anderson et al., 1989; Herrmann et al., 1991; Kawano et al., 1988; Klein et al., 1989). Numerous cytokines including IL-6, GMCSF, G-CSF, IL-11, IL-1 and TNF are produced in short-term cultures of myeloma tumor tissue in about half of the MM patients (Carter et al., 1990; Cozzolino et al., 1989; Facon et al., 1993; Klein et al., 1989; Zhang et al., 1990, 1992). Among these growth factors, IL6 is the most important one since almost complete inhibition of proliferation is achieved by anti-IL-6 monoclonal antibody (Zhang et al., 1992).

Secretion of IL- 6 from BMSC is upregulated by MM cell adherence, CD40, TNF- $\alpha$, VEGF, TGF- $\beta$ and IL-1 $\beta$ (Dinarello, 2011). Additionally, NF- $\kappa$ B plays an important role in IL-6 upregulation (Chauhan et al., 1997). After binding to its receptors, IL-6 triggers the activation of MEK/MAPK, JAK/STAT3 and PI3K/Akt signaling pathways and induces proliferation of myeloma cells via activation of RAS/Raf/MEK-ERK signaling pathway (Hideshima et al., 2007, 2001). GM-CSF, IL-3 and IL-5 stimulate the proliferation of myeloma cells indirectly by amplifying myeloma cells' response to IL-6 (Weiss et al., 2009; Zhang et al., 1992).

Several cytokines such as IFN- $\alpha$ and TNF can stimulate growth of myeloma cells by inducing autocrine production of IL-6 (Jourdan et al., 1991). On the other hand, IFN- $\gamma$ is able to inhibit IL6-dependent myeloma cell proliferation by downregulating the expression of $\alpha$ chain of the IL- 6 receptor complex (Portier et al., 1993).

Insulin-like growth factor (IGF-1) which is secreted by BMSC and osteoblasts induces growth, survival and migration of MM cells via MAPK and PI3K/Akt signaling pathway (De Bruyne et al., 2010). Activation of Akt leads to activation of the anti-apoptotic proteins such as Bcl- $\mathrm{X}_{\mathrm{L}}$ and Bcl-2 (Pollak, 2008).
Table 2

Treatment strategies of MM.

\begin{tabular}{ll}
\hline I. & Chemotherapy \\
II. & High-dose chemotherapy with hematopoietic \\
& stem cell transplant \\
III. & Radiation \\
IV. & Maintenance therapy \\
V. & Supportive care \\
VI. & Management of drug-resistance or refractory \\
& disease \\
VII. & - Thalidomide, Revlimid ${ }^{\circledR}$, next generation \\
& ImiD, pomalidomide \\
& - VELCADE ${ }^{\circledR}$ and next generation proteasome \\
& inhibitors (carfilzomib, NPI-0052) \\
& - Doxil ${ }^{\circledR}$ (pegylated liposomal doxorubicin) \\
& Mini-allo (non-myeloablative) transplant \\
& Histone deacetylase inhibitors (vorinostat, \\
& panobinostat) \\
& Monoclonal antibodies (elotuzumab)
\end{tabular}

Table 3

Commonly used chemotherapeutic drugs in MM.

\begin{tabular}{|c|c|}
\hline Traditional drugs & Novel agents \\
\hline Melphalan (Alkeran ${ }^{\circledR}$ ) & Pegylated, liposomal doxorubicin (Doxil ${ }^{\circledR}$ ) \\
\hline Cyclophosphamide (Cytoxan ${ }^{\circledR}$ ) & Bortezomib (VELCADE ${ }^{\circledR}$ ) \\
\hline Prednisone (Prednisolone ${ }^{\circledR}$ ) & Thalidomide (Thalomid ${ }^{\circledR}$ ) \\
\hline Dexamethasone (Decadron ${ }^{\circledR}$ ) & Lenalidomide (Revlimid ${ }^{\circledR}$ ) \\
\hline \multicolumn{2}{|l|}{ Vincristine (Oncovin ${ }^{\circledR}$ ) } \\
\hline \multicolumn{2}{|l|}{ Doxorubicin (Adriamycin ${ }^{\circledR}$ ) } \\
\hline \multicolumn{2}{|l|}{ Busulphan (Myleran ${ }^{\circledR}$ ) } \\
\hline \multicolumn{2}{|l|}{ VP-16 (Etoposide ${ }^{\circledR}$ ) } \\
\hline Cisplatin (Platinol ${ }^{\circledR}$ ) & \\
\hline
\end{tabular}

\section{Treatment strategies in multiple myeloma}

In the decision of MM treatment, one of the most important parameters is to determine if treatment is required since patients with MGUS and asymptomatic myeloma should be observed closely rather than treated (Alexanian, 1980; Kyle and Greipp, 1980). Anti-myeloma treatment is recommended when symptomatic myeloma has developed. It is reflected by an increase in M-component and development of "CRAB" that refers to: Calcium elevation; Renal problems; Anemia; or Bone issues (Brian and Durie, 2015). There are different treatment protocols for MM as shown in Table 2.

\subsection{Chemotherapy}

Chemotherapy is the mostly preferred treatment strategy for MM and it has different approaches, which are listed in Table 3.

In 1962, melphalan was introduced as the first specific drug for treatment of myeloma (Brian and Durie, 2015). Oral administration of melphalan and prednisone has remained a standard form of therapy for almost 50 years (Huang et al., 1999). Treatment with this regimen yields a response rate of about $50 \%$ with a few complete remissions, an average remmission duration of approximately 18 months and a medium survival of 24-30 months (Oken, 1984). The reported 5-year survival rate is less than $20 \%$ (Bergsagel, 1988). However, melphalan can damage bone marrow stem cells and obviously, it is not a good choice for the patients that are planning for stem cell harvest (Brian and Durie, 2015).

Due to the limitation and insufficient success of the standard chemotherapy, a combination of multiple chemotherapeutic 
agents began to be used in MM treatment. M-2 protocol consisting of vincristine, nitrosourea carmustine, melphalan, cyclophosphamide and prednisone (VBMCP) is one of the best known among the regimens which were devised at Memorial Sloan-Kettering Cancer Center in 1977. Later on, the Eastern Cooperative Oncology Group (ECOG) conducted a large randomized study comparing the treatment of melphalan with VBMCP regimen. Results gathered demonstrated that VBMCP induced a higher response rate (72\%), a large response duration (24 months) and a slightly higher 5-year survival rate (26\%).

In refractory and relapsing myeloma patients, vincristine, doxorubicine and dexamethasone (VAD), cyclophosphamide and etoposide (Cy-E) and regimens consisting of etoposide, cisplatin, cytarabine and dexamethasone were used (Alexanian et al., 1986; Ballester et al., 1997). However, vincristine is no longer commonly used as a part of the VAD regimen, which was shown to be inferior to bortezomib, doxorubicin and dexamethasone (Brian and Durie, 2015).

In recent years, with the introduction of novel agents such as thalidomide, bortezomib and lenalidomide, treatment approaches have changed on a vast scale. For the older patients or the patients who are not suitable for transplantation, melphalan/prednisone/thalidomide (MPT), bortezomib/melphalan/prednisone(VMP), thalidomide/dexamethasone (TD) and lenalidomide/low-dose dexamethasone (RevloDex) regimens are used (Brian and Durie, 2015). On the other hand Thal/Dex (TD), VELCADE ${ }^{\circledR} / \operatorname{Dex}(\mathrm{VD}), \mathrm{VELCADE}^{\circledR} /$ Thalidomide/Dex (VTD) and Revlimid ${ }^{\circledR} /$ Low-dose Dex (RevloDex-Rd) are the regimens used for the induction therapy for transplant candidates (Brian and Durie, 2015).

\subsection{High-dose chemotherapy with autologous stem cell transplantation}

High-dose chemotherapy is used as a part of transplantation schedules, either with total body irradiation or as a single agent at very high dosage. High-dose melphalan and other highdose therapies such as high-dose cyclophosphamide or high-dose cyclophosphamide and etoposide with growth factor support are also used in relapsed and refractory patients (Dimopoulos et al., 1993; Huang et al., 1999; Lenhard et al., 1984).

\subsection{Radiotherapy}

Radiotherapy is also used in the treatment of MM in addition to chemotherapy. Radioactive cobalt-60 is extensively used in the treatment of multiple myeloma (De Laeter et al., 2000).

Radiation therapy can be used in several ways in myeloma such as;

I Local radiation therapy at higher doses, in addition to chemotherapy in some cases, is used in the treatment of solid tumors in bone or soft tissue.

II High-dose radiation to a larger part of the body can be used to reduce tumor burden.

III Total body irradiation is used with high-dose chemotherapy prior to stem cell transplantation.

IV Local low-dose radiation is sometimes used as a palliative treatment to relieve uncontrolled pain and to prevent or treat bone fractures.

\section{Multidrug resistance in multiple myeloma}

Multidrug resistance is the major problem for the effective treatment of multiple myeloma to the conventional chemotherapy and/or radiotherapy, not all patients respond well and even in responding patients, either complete remissions are rare or relapse occurs (Van Hoeven et al., 1990). Multiple myeloma has been shown to be commonly MDR-negative at diagnosis and associated with a high incidence of MDR expression at relapse. There is a progressive increase in the incidence of MDR expression with increasing exposure to chemotherapeutic agents (Dalton et al., 1989; Grogan et al., 1993).

The emergence of drug-resistance in cancer cells is a major complication for effective chemotherapy. In multidrug resistance, cancer cells exhibit cross-resistance to a broad spectrum of structurally unrelated drugs. Drug resistance can be either intrinsic or acquired. In intrinsic drug resistance, cancer cells are insensitive to chemotherapy at the beginning of treatment. However, in acquired resistance, malignant cells are initially sensitive to particular chemotherapy regimen but later become progressively unresponsive to the same or different antitumoral drugs (Klappe et al., 2004). Malignant cells may exhibit genetic instability allowing spontaneous generation of variant forms, which may result in drug resistance. Cancer stem cells (CSCs) in both solid and hematologic malignancies are referred to as cancer initiating cells which are resistant to chemotherapy due to their ability to self-renew, differentiate and remain relatively quiescent features (Cairo et al., 2010; Tan et al., 2010). There are several mechanisms of drug resistance such as reduced intracellular drug accumulation, altered drug distribution within the cell, modification of the drug target, enhanced ability to repair drug damage and inhibiton of apoptosis (Ueda et al., 1987). Overcoming drug resistance is very complicated since when one mechanism of resistance is eliminated, cancer cells can adapt and become resistant by another mechanism. Therefore, it is necessary to adress multiple mechanisms in order to overcome drug resistance completely (Dalton et al., 2002).

\subsection{Differential expression levels of $A B C$ transporter protein family members}

The main mechanism controlling MDR is overexpression of an ATP-dependent efflux pump known as P-glycoprotein (P-gp). This protein is encoded by MDR1 gene and is the first known member of $A B C$ (ATP-binding cassette) transporter superfamily (Raaijmakers, 2007). ABC transporters are responsible for the transport of a wide variety of substrates including ions, phospholipids, steroids, polysaccharides, amino acids and peptides across biological membranes (Ambudkar et al., 1999). It was shown that P-gp is overexpressed in drug resistant cancer cells and pumps out the drugs by reducing their intracellular concentration. Other members of transporter superfamily which are important in drug resistance include multidrug resistance associated protein (MRP1), breast cancer resistance protein (BCRP) and lung resistance related protein (LRP) (Marie, 2001).

$\mathrm{P}$-gp expression was not detected in de novo diagnosed MM cases and in patients treated with melphalan (Grogan et al., 1993). In MM, P-gp overexpression was shown to be associated with vincristine, doxorubicine, etoposide and glucocorticoid resistance (Dalton, 1997). In addition to P-gp, BCRP activity was linked with an unfavorable therapy outcome in MM (Turner et al., 2006). BCRP was found to be expressed in the mitoxantrone-selected human MM cell line 8226 (Ross et al., 1999). Recently, it has been reported that bortezomib is a substrate for P-gp but not for the other drug efflux transporters, and it dirrectly affects the expression and function of P-gp (O'Connor et al., 2013). However, this finding is not supported by other studies (Wang and La, 2013). On the other hand, it was shown that overexpression of P-gp is responsible for the resistance to a new second generation proteasome inhibitor, carflizomib (Hawley et al., 2013). MRP1 overexpression generally was not detected in MM cells (Lynsenmeyer et al., 1992; Marie, 2001). LRP expression was detected in approximately half of MM 
patients and is associated with a poor response to melphalan-based induction chemotherapy (Lokhorts et al., 1996).

\subsection{Bone marrow microenvironment and cell adhesion}

Bone marrow microenvironment (BMME) plays a critical role in myeloma cell survival and environment-mediated drug resistance (Anderson and Carrasco, 2011; Hideshima et al., 2007; Manier et al., 2012). MM cells adhere to BMSCs or fibronectin leading to maintaining cell proliferation, growth and invasion (Chauhan et al., 1996). Cell adhesion also has been shown to prevent cell death through a number of mechanisms, such as soluble factor-mediated drug resistance (SFM-DR) and cell-adhesion mediated drug resistance (CAM-DR) (Meads et al., 2009). SFM-DR and CAM-DR usually work together within the bone marrow environment (Fig. 1) (Abdi et al., 2013). SFM-DR can be explained by involvement of IL-6. It has been shown to promote cell survival by enhancing adhesion of myeloma cells to bone marrow and fibronectin, through macrophage inflammatory protein- $1 \alpha$. Macrophage inflammatory protein- $1 \alpha$ is secreted by myeloma cells and was found to be elevated in the bone marrow plasma of the majority of patients with advanced MM (Dalton et al., 2002). On the other hand, CAM-DR is mediated by adhesion of myeloma cells to BMSCs or ECM proteins by $\beta 1$ integrins (Alberts et al., 2004). When myeloma cells adhere to fibronectin, they become resistant to multiple drugs, including doxorubicin and melphalan (Dalton et al., 2002). However, different types of ECM components were altered in different drug resistant MM cells. Integrin alpha L (ITGAL) and integrin beta 2 (ITGB2) are highly expressed in vincristine resistant RPMI-8226 cells whereas they were both downregulated in prednisone resistant subline. On the other hand, Laminin Gamma 1 (LAMC1) was drastically overexpressed in prednisone resistant subline whereas it was downregulated in its melphalan resistant variant. Fibronectin 1 (FN1) gene was only upregulated in vincristine resistant RPMI8226 cells. ADAM metallopeptidase domain 17 gene was only upregulated in melphalan resistant subline. Additionally, collagen type XXI, alpha 1 (COL21A1) was drastically downregulated in prednisone, melphalan and vincristine resistant sublines of RPMI8226 MM cells (Mutlu et al., 2012). High levels of IGF-1 cytokine was shown to be associated with bortezomib resistance (Kuhn et al., 2012). CAM-DR to doxorubicin, melphalan, vincristine, bortezomib and mitoxantrone have been induced in MM through adhesion to FN or BMSCs by VLA4 integrin $(\alpha 4 \beta 1)$ and IEA-1 (Noborio-Hatano et al., 2009; Schmidmaier et al., 2004).

\subsection{Deregulation of cell cycle and apoptosis mechanisms}

Signaling molecules, scaffolds, complexes and mediators in a varity of signaling pathways related to cell cycle and apoptosis could possibly mediate drug resistance (Abdi et al., 2013). The balance between cell proliferation and apoptosis is a critical phenomenon both for development and normal tissue homeostasis. Deregulation of these processes in a normal cell resulted in cancer and also drug resistance phenotype during the treatment (Fotedar et al., 1996).

Cell cycle progression is controlled by external and internal signals. The events throughout the cell cycle are controlled by cyclins and cyclin-dependent kinases at the checkpoints on the cell cycle (Kaldis et al., 1998; Libermann et al., 1995). Cell cycle mediated drug resistance, ekleyelim which is described as relative insensitivity to chemotherapeutics owing to the position of the cells in the cell cycle, is one of the other important problems during chemotherapy (Chan et al., 2000; Motvani et al., 1999). Cell cycle mediated drug resistance was shown in several drug resistant cancer cell lines. In vincristine resistant MM U-266 cell line, there were significant increases in expression levels of various cyclin dependent kinases such as cyclin-dependent kinase 10 (CDK10), cyclin-dependent kinase 3 (CDK3), cyclin-dependent kinase 4 (CDK4) and cyclin E2 (Mutlu et al., 2014). In addition, some of the cyclin dependent kinase inhibitor encoding genes (BCCIP, CDKN1A, CDKN1C, CDKN2B) were downregulated in corticosteroid, vincristine and melphalan resistant U-266 MM cells (Mutlu et al., 2014).

p53 tumor suppressor gene is responsible for the control of many important mechanisms in the cell such as cell cycle, apoptosis, autophagy and DNA repair (Saha et al., 2013). p53 is inactivated in 10-12\% of MM cases (Avet-Loiseau et al., 1999; Chng et al., 2007) resulting from either $p 53$-DNA binding domain mutations or overexpression of murine double minute 2 gene (MDM2) (Farnebo et al., 2010). MDM2, an E3-ubiquitin ligase, binds p53 to ubiquitinate and targets it for degradation through ubiquitin/proteasome pathway (Piette et al., 1997). Its overexpression is detected approximately in $58 \%$ of MM cases and generally is associated with resistance to vincristine, doxorubicin and etoposide (Cocker et al., 2001; Elnenaei et al., 2003; Rayburn et al., 2005).

NF-кB, an important transcription factor, has an important role in $\mathrm{MM}$ pathogenesis, expansion and drug resistance (Anderson and Carrasco, 2011; Demchenko et al., 2010). Recently, it has been shown that mutations in some genes of NF- $\mathrm{B}$ pathway result in constitutive activation of NF- $\kappa \mathrm{B}$ signaling making MM cells more resistant to chemotherapy (Chapman et al., 2011; Keats et al., 2007). The apoptotic function of bortezomib is partly explained by blocking canonical NF-кB pathway. However, in bortezomib resistance, it induces the alternative non-canonical pathway (Fabre et al. 2012). Bortezomib resistance may also develop through proteasome inhibitor resistant (PIR) pathway (Markovina et al., 2008). NF- $\kappa \mathrm{B}$ could also contribute to drug resistance through upregulation of some anti-apoptotic Bcl-2 family proteins (Xiang et al., 2011).

There is a balance between pro-apoptotic and anti-apoptotic proteins following TNF-R1 and Fas activation in direct transduction process of apoptosis. Caspases play the central role in apoptosis. It was demonstrated that tumor necrosis factor alpha-induced protein 3 (TNFAIP3) and tumor necrosis factor receptor superfamily member 10d (TNFRSF10) were downregulated in corticosteroid resistant MM U-266 cells whereas tumor necrosis factor-inducible gene 6 protein (TNFAIP6) and tumor necrosis factor alpha-induced protein 8 (TNFAIP8) were upregulated in vincristine resistant cells (Mutlu et al., 2014). Moreover, different types of effector caspases (caspase 3, -6, and -7) were downregulated in corticosteroid, vincristine and melphalan resistant U-266 MM cells indicating their role in drug resistance (Mutlu et al., 2014). On the other hand, Bcl2 overexpression and Noxa/Bcl-2 protein interactions conribute to bortezomib resistance in human lymphoid cells (Smith et al., 2011).

Alterations in the sphingolipid composition are also related to anti-apoptotic behavior of multidrug resistant cells. Sphingolipids including ceramide and sphingosine regulate the differentiation, proliferation, apoptosis and drug resistance (Haimovitz-Friedman et al., 1994). Ceramide accumulation inside the cell due to the overexpression of ceramide synthase genes triggers apoptosis. Overexpression of glycosylceramide appears to be a rather general aspect of P-gp expressing MDR cells (Klappe et al., 2004). Glycosylceramide synthase overexpression was shown to enhance resistance to doxorubicin and alterations of ceramide/sphingosine 1-phosphate was shown to be involved in the regulation of resistance to imatinib in K562CML cells (Baran et al., 2007). In addition, expression of glusosylceramide synthase mRNA in vincristineresistant KBV200 cells and imatinib resistant K562 cells was shown in association with multidrug resistance (Baran et al., 2011; Yang et al., 2004). Ceramide metabolising genes altered in melphalan resistance in favor to survive U-266 MM cells. Melphalan resistant subline of U-266 tend to decrease ceramide level via downregulating sphingomyelinase and ceramide synthase genes 


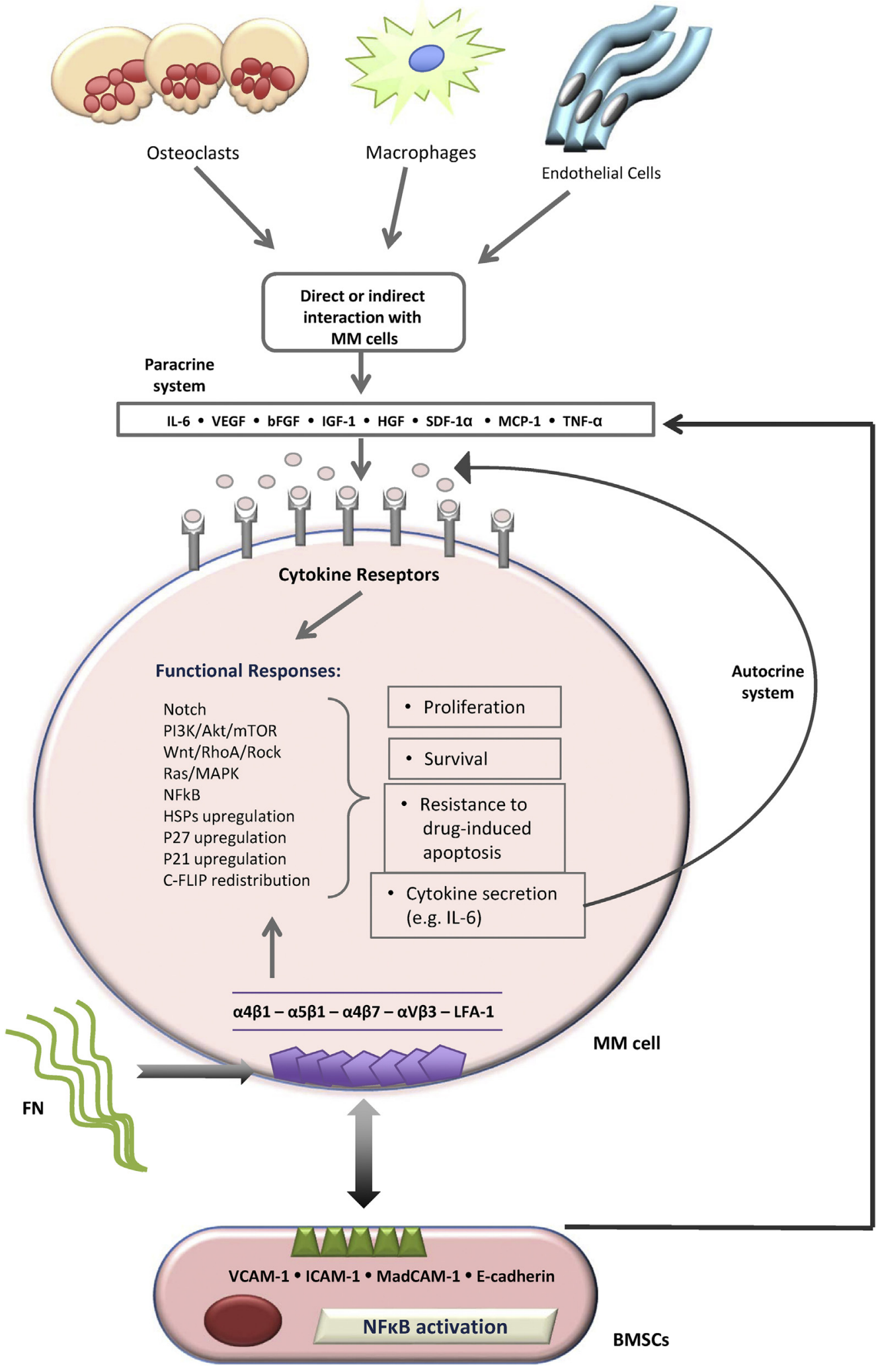

SFM-DR

Fig. 1. Mechanisms of soluble factor-mediated drug resistance (SFM-DR) and cell-adhesion mediated drug resistance (CAM-DR) (Abdi et al., 2013).

while upregulating sphingosine kinase and glucosyleceramide synthase genes (Mutlu et al., 2014).

A recent study emphasizes the importance of autophagy process in chemotherapy resistance. The study demonstrated that the cellular process of autophagy may allow cancer cells to recover and divide rather than die when faced with chemotherapeutic agents. In autophagy, initially mitochondrial membrane breaks down and proteins are released from mitochondria in a process known as canonical death receptor-induced mitochondrial outer membrane permeabilization (MOMP), which is considered as a 
common marker of cell death. However, high autophagy allows the cell to encapsulate and "digest" these released proteins before MOMP can keep the cell wall and truly die. At last, cancer cells recover and continue to divide. On the other hand, autophagy depends on target PUMA to regulate cell death. Specifically, when PUMA is suppressed, it does not matter if autophagy is inhibited by the absence of communicating action of PUMA and cancer cells continue to survive (Thorburn et al., 2014).

\subsection{Cross-resistance to radiation}

Cobalt-60 gamma radiation is also used in the treatment of multiple myeloma. MM patients sometimes receive radiotherapy in addition to chemotherapy. Even combination of chemotherapy and radiotherapy can result in the emergence of clinical drug resistance (Dalton and Jove, 1999). In the literature, it was demonstrated that vincristine-resistant RPMI-8226 and U-266 MM cells did not show any cross-resistance when exposed to $\gamma$-radiation and vincristine-resistant sublines were radiosensitive (Mutlu et al., 2011). In addition, the results of other studies showed that paclitaxel enhanced tumor radio response (Choy et al., 1993; Klappe et al., 2004; Liebmann et al., 1994; Milas et al., 1994). Both vincristine and paclitaxel are chemotherapeutic agents that stabilize microtubule activity and arrest cells in $G_{2}-M$ phase. $G_{2}$ and $M$ phases are the most radiosensitive phases of the cell cycle so both paclitaxel and vincristine have the potential as cell cycle specific radiosensitizers (Klappe et al., 2004). Conversely, prednisone and melphalan-resistant RPMI-8226 cells are cross-resistant to $\gamma$ radiation (Mutlu et al., 2011). The mechanisms responsible for the cross-resistance between radiation and melphalan have been studied in human ovarian cancer cells and the results have revealed that melphalan resistant cells have increased cellular levels of GSH and are cross resistant to radiation. In addition, depletion of GSH levels led to a marked sensitization to irradiation (Milross et al., 1997).

There are not many reports which contributed to overcoming radiotherapy resistance in MM. However, it was demonstrated by Supiot et al. (2007) that Gemcitabine gives rise to radiosensitization of LP1 and U-266 MM cells when combined with cobalt-60.

\section{Overcoming drug resistance in multiple myeloma}

Cells exhibiting the MDR phenotype can become responsive to chemotherapy by treatment with MDR-reversing agents. These agents come from a diverse group of drugs that includes several membrane active agents, calmodulin antagonists, calcium channel blockers, local anesthetics and cyclosporine (Sikic, 1993).

Inhibition of P-gp activity has become a major target in order to overcome drug resistance. Several MDR modulators have been used to reverse drug resistance in MM. In the literature, verapamil and quinine were indicated to be the most commonly studied MDR reversal agents that may be used together with VAD regimen but this combined therapeutic strategy resulted in significant cardiac toxicity (Dalton et al., 1995; Fisher et al., 1996). Cyclosporine is another MDR modulator that has been used together with the VAD regimen. However, its addition to chemotherapy resulted in a high incidence of neurotoxicity and myelosuppression (Sonneveld et al., 1992b). PSC 833, an analogue of Cyclosporine D, appears to have a high binding affinity to P-glycoprotein but to be less toxic (Jonsson et al., 1992; Sonneveld et al., 1992a).

NF- $\kappa \mathrm{B}$ activity also induces chemotherapy resistance and the inhibition of its activity could reverse the chemotherapy-resistant phenotype (Cusack et al., 1999). Arsenite has been shown to be a potent NF-кB inhibitor (Kapahi et al., 2000). Arsenite can sensitize myeloma cells to chemotherapy if it is used with other chemotherapeutic agents (Yang et al., 2003).
Besides NF- $\kappa$ B, antiapoptotic proteins such as Bcl-2 and Bcl$\mathrm{X}_{\mathrm{L}}$ also contribute to the resistance of various chemotherapeutic agents including cyclophosphamide, methotrexate, antracycline, cytarabine and corticosteroids (Wuchter et al., 1999). Bcl-2 antisense oligonucleotide (Bcl-2 ASO) was shown to be quite effective in sensitizing the drug-resistant MM cells (Gazitti et al., 2001).

Antiapoptotic effects of JAK-STAT3 signaling could be reversed by applying a specific inhibitor of JAK family kinases, AG490. Through inhibition of JAK-STAT signaling, expression of Bcl- $\mathrm{X}_{\mathrm{L}}$ can be suppressed (Damiano et al., 1999).

New proteasome inhibitors such as Carfilzomib, Marizomib, ONX 0912, MLN 9708; HDAC inhibitors; new ImiDs; kinase inhibitors of mTOR, HSP90 and new antibodies against CS-1, CD38, and IL-6 were shown to be very effective in combination with conventional drugs (Gentile et al., 2013; Lonial et al., 2011; Misso et al., 2013).

\section{Targeted drug therapy approaches}

Although the emergence of new drugs has revolutionized MM therapy, almost all of MM patients eventually develop drug resistance (Abdi et al., 2013). In recent years, with improvements in nanotechnology, nanocarrier-mediated drug delivery has emerged as a successful strategy to enhance delivery of therapeutics to the tumor site (Matsumura and Maeda, 1986). This is also known as targeted drug delivery providing differential distribution of drugs to the tumor site while significantly reducing the overall toxicity (Manish and Vimukta, 2011). Nanocarriers are the particles with nanosize that can be fabricated from a multitude of materials in a variety of compositions including polymeric, liposomal, dendrimeric and magnetic ones (Nune et al., 2009).

Magnetic nanoparticles, which can be targeted to the tumor site in a magnetic field, have gained importance in cancer therapy in recent years. They can be coated with different kinds of polymers, readily modified with biocompatible coatings and loaded with therapeutic agents (Gupta and Gupta, 2005; Sun et al., 2008). Furthermore, conjugation of special targeting moieties such as sugar, folic acid, biotin, antibody, peptide and growth factors to nanocarrier systems can lead to preferential distribution of the cargo in the targeted tissue (Majoros et al., 2006, 2005).

Manifestation of these targeted drug delivery strategies in clinical approaches is possible in near future and they are promising for the complete treatment of relaps or drug resistant cases of many cancer types including multiple myeloma.

\section{Conclusion and future directions}

Development of MM proceeds of numerous molecular events, including chromosomal abnormalities, oncogene activation, and growth factor dysregulation. Moreover, microenvironment of bone marrow also plays an important role during the evolution of myeloma. There are several treatment strategies for MM, in which chemotherapy is most commonly used one. However, the emergence of drug-resistance during the treatment is a major complication for the effective chemotherapy. On the other hand, overcoming the drug resistance is very complicated. Therefore, it is necessary to adress multiple mechanisms to overcome drug resistance. Development of new strategies in the targeted drug delivery systems with the improvements in nanotechnology gained importance in recent years. As research progresses, there will be opportunity for the manifestation of these targeted drug delivery systems in clinical studies for the treatment of relaps and drug resistant cases in MM. 


\section{Conflict of interest}

None of the authors have any interests which might influence the compilation of the current literature in this subject. We apologize to the authors whose valuable studies were not included here due to space limitations and the concentrated scope of the review.

\section{References}

Abdi, J., Chen, G., Chang, H., 2013. Drug resistance in multiple myeloma: latest findings and new concepts on molecular mechanisms. Oncotarget 4 2186-2207.

Alberts, B., Bray, D., Hopin, K., Johnson, A., Lewis, J., Raff, M., Roberts, K., Walter, P., 2004. Tissue and cancer. In: Essential Cell Biology. Gorland Science, New York and London.

Alexanian, R., Borlogie, B., Dixon, D., 1986. High dose glucocorticoid treatment of resistant myeloma. Ann. Intern. Med. 105, 8-11.

Alexanian, R., 1980. Localized and indolent myeloma. Blood 56, 521-525.

Altieri, A., Gallus, S., Franceschi, S., Fernandez, E., Talamini, R., La Vecchia, C., 2004. Hormone replacement therapy and risk of lymphomas and myelomas. Eur. J. Cancer Prev. 13, 349-351.

Ambudkar, S.V., Dey, S., Hrycyna, C.A., Ramachandra, M., Pastan, I., Gottesman, M.M., 1999. Biochemical, cellular and pharmacological aspects of the multidrug transporter. Ann. Rev. Pharmacol. Toxicol. 9, 361-398.

American Cancer Society, 2005. Cancer Facts and Figures, 2005. American Cancer Society, Atlanta.

Anderson, K.C., Carrasco, R.D., 2011. Pathogenesis of myeloma. Annu. Rev. Pathol. 6, 249-274.

Anderson, K.C., Jones, R.M., Morimoto, C., et al., 1989. Response patterns of purified myeloma cells to hematopoietic growth factors. Blood 73, 1915-1924.

Avet-Loiseau, H., Li, J.Y., Godon, C., Morineau, N., Daviet, A., Harousseau, J.L., facon, T., Bataille, R., 1999. P53 deletin is not a frequent event in multiple myeloma. Br. J. Haematol. 106, 717-719.

Avet-Loiseau, H., Attal, M., Moreau, P., et al., 2007. Genetic abnormalities and survival in multiple myeloma: the experience of the Intergroupe Francophone du Myelome. Blood 109, 3489-3495.

Ballester, O.F., Mascinski, L.C., Fields, K.K., Hiemenz, J.W., Zorsky, P.E., Goldstein, S.C., Saba, H.I., Spiers, A.S., Kronish, L., Sullivan, P., Elfenbein, G.J., 1997. Dexamethasone, cyclophosphamide, idarubicine and etoposide (DC-IE): a novel, intensive induction chemotherapy regimen for patients with high-risk multiple myeloma. Br. J. Haematol. 96, 746-748.

Baran, Y., Salas, A., Senkal, C.E., Gunduz, U., Bielawski, J., Obeid, L.M., Ogretmen, B. 2007. Alterations of ceramide/sphingosine 1-phosphate rheostat involved in the regulation of resistance to imatinib-induced apoptosis in K562 human chronic myeloid leukemia cells. J. Biol. Chem. 282, 10922-10934.

Baran, Y., Bielawski, J., Gunduz, U., Ogretmen, B., 2011. Targeting glucosylceramide synthase sensitizes imatinib-resistant chronic myeloid leukemia cells via endogenous ceramide accumulation. J. Cancer Res. Clin. Oncol. 137 (10) 1535-1544.

Barlogie, B., Shaughnessy, J., Epstein, J., et al., 2005. Plasma cell myeloma. In: Kaushansky, K., Lichtman, M.A., Beutler, E. (Eds.), Williams Hematology. , 7th ed. McGraw-Hill Professional, New York, pp. 1501-1533.

Bataille, R., Chappard, C., Marcelli, C., et al., 1989. Mechanisms of bone destruction in multiple myeloma: the importance of an unbalanced process in determinig the severity of lytic bone disease. J. Clin. Oncol. 7, 1909-1914.

Benedict, W.F., Xu, H.J., Hu, S.X., Takahashi, R., 1990. Role of the retinoblastoma gene in the initiation and progression of human cancer. J. Clin. Invest. 85, 988-993.

Bergsagel, P.L., Kuehl, W.M., 2001. Chromosome translocations in multiple myeloma. Oncogene 20, 5611-5622.

Bergsagel, P.L., Kuehl, W.M., 2005. Molecular pathogenesis and a consequent classification of multiple myeloma. J. Clin. Oncol. 23, 6333-6338.

Bergsagel, D.E., 1988. Use a gentle approach for refractory myeloma patients. J. Clin. Oncol. 6, 757-758.

Blair, C.K., Cerhan, J.R., Folsom, A.R., Ross, J.A., 2005. Anthropometric characteristics and risk of multiple myeloma. Epidemology 16, 691-694.

Botallie, R., Harousseau, J.L., 1997. Multiple myeloma. N. Engl. J. Med. 336, 1657-1664.

Bottura, C., 1963. Chromosomal abnormalities in multiple myeloma. Acta Haematol. 30, 274-279.

Brian, G.M., Durie, M.D., 2015. Concise review of the disease and treatment options. In: Multiple Myeloma, Cancer of the Bone Marrow. International Myeloma Foundation 2011/2012 Edition.

Brown, L.M., Gibson, R., Burmeister, L.F., Schuman, L.M., Everett, G.D., Blair, A., 1992. Alcohol consumption and risk of leukemia, non-Hodgkin's lymphoma, and multiple myeloma. Leuk. Res. 16, 979-984.

Brown, L.M., Pottern, L.M., Silverman, D.T., Schoenberg, J.B., Schwartz, A.G., Greenberg, R.S., Hayes, R.B., Liff, J.M., Swanson, G.M., Hoover, R., 1997. Multiple myeloma among blacks and whites in the United States: role of cigarettes and alcoholic beverages. Cancer Causes Control 8, 610-614.

Brownson, R.C., 1991. Cigarette smoking and risk of myeloma. J. Natl. Cancer Inst. $83,1036-1037$
Cairo, M.S., Jordan, C.T., Maley, C.C., Chao, C., Melnick, A., Armstrong, S.A., Shlomchik, W., Molldrem, J., Ferrone, S., Mackall, C., Zitvogel, L., Bishop, M.R., Giralt, S.A., June, C.H., 2010. NCI first International Workshop on the biology, prevention, and treatment of relapse after allogeneic hematopoietic stem cell transplantation: report from the committee on the biological considerations of hematological relapse following allogeneic stem cell transplantation unrelated to graft-versus-tumor effects: state of the science. Biol. Blood Marrow Transpl. 16, 709-728.

Caligaris-Cappio, F., Gregoretti, M.G., Ghia, Bergui, L., 1992. In vitro growth of human multiple myeloma: implications for biology and therapy. Hematol. Oncol. Clin. North Am. 6, 257-271.

Carter, A., Merchav, S., Silvian-Draxler, I., Tatarsky, I., 1990. The role of interleukin- 1 and tumor necrosis factor- $\alpha$ in human multiple myeloma. Br. J. Haematol. 74, 424-431.

Chan, T.A., Hwang, P.M., Hermeking, J., Kinzler, K.W., Vogelstein, B., 2000. Cooperative effects of genes controlling the G2/M checkpoint. Genes Dev. 14 1584-1588.

Chapman, M.A., Lawrence, M.S., Keats, J.J., Cibulskis, K., Sougnez, C., Schinzel, A.C. Harview, C.L., Brunet, J.P., Ahmann, G.J., Adli, M., Anderson, K.C., Ardlie, K.G., Auclair, D., Baker, A., Bergsagel, P.L., Bernstein, B.E., et al., 2011. Initial genome sequencing and analysis of multiple myeloma. Nature 471 (7339), 467-472.

Chauhan, D., Uchiyama, H., Akbarali, Y., Urashima, M., Yamamoto, K., Libermann, T.A., Anderson, K.C., 1996. Multiple myeloma cell adhesion-induced interleukin-6 expression in bone marrow stromal cells involves activation of NF-kappa B. Blood 87, 1104-1112.

Chauhan, S., Kharbanda, S., Ogata, A., et al., 1997. Interleukin-6 inhibits Fas-induced apoptosis and stress-activated protein kinase activation in multiple myeloma cells. Blood 89, 227-234.

Chesi, M., Nardini, E., Lim, R.S., et al., 1998. The t(4;14) translocation in myeloma dysregulates both FGFR3 and a novel gene, MMSET, resulting in IgH/MMSET hybrid transcripts. Blood 92, 3025-3034.

Chng, W.J., Price-Troska, T., Gonzalez-Paz, N., Van Wier, S., Jacobus, S., Blood, E. Henderson, K., Oken, M., Van Ness, B., Greipp, P., Rajkumar, S.V., Fonseca, R. 2007. Clinical significance of TP53 mutation in myeloma. Leukemia 21, $582-584$.

Choy, H., Rodriguez, F.F., Koester, S., Hilsenbeck, S., Von Hoff, D.D., 1993. Investigation of taxol as a potential radiation sensitizer. Cancer 71, 3774-3778. Cocker, H.A., Hobbs, S.M., Tiffin, N., Pritchard-Jones, K., Pinkerton, C.R., Kelland, L.R. 2001. High levels of the MDM2 oncogene in paediatric rhabdomyosarcoma cell lines may confer multidrug resistance. Br. J. Cancer 85 (11), 1746-1752.

Cohen, H.J., Crawford, J., Rao, M.K., Pieper, C.F., Currie, M.S., 1998. Racial differences in the prevalence of monoclonal gammopathy in a community-based sample of the elderly. Am. J. Med. 104, 439-444.

Corradini, P., Inghirami, G., Astolfi, M., 1994. Inactivation of tumor suppressor genes, p53, and Rb1 in plasma cell dyscrasias. Leukemia 8, 758-767.

Cozzolino, F., Torcia, M., Aldinucci, D., et al., 1989. Production of interleukin-1 by bone marrow myeloma cells. Blood 74, 380-387.

Cusack, J., Liu, R., Baldwin, A., 1999. NF-kappa-B and chemoresistance potentiation of cancer chemotherapy via inhibition of NF-kappa-B. Drug Resist. Updat. 2, 271-273.

Dalton, W.S., Jove, R., 1999. Drug resistance in multiple myeloma: approaches to circumvention. Semin. Oncol. 26, 23-27

Dalton, W.S., Grogan, T.M., Rybski, J.A., Scheper, R.J., Richter, L., Kailey, J., Broxterman, H.J., Pinedo, H.M., Salmon, S.E., 1989. Immunohistochemical detection and quantitation of P-glycoprotein in multiple drug resistant human myeloma cells: association with level of drug resistance and drug accumulation. Blood 73, 747-752

Dalton, W.S., Crowley, J.J., Salmon, S.S., et al., 1995. A phase III randomized study of oral verapamil as a chemosensitizer to reverse drug resistance in patients with refractory myeloma: a Southwest Oncology Group Study. Cancer 75, 815-820.

Dalton, W.S., et al., 2002. Drug resistance and drug development in multiple myeloma. Semin. Oncol. 29, 21-25.

Dalton, W.S., 1997. Detection of multidrug resistance gene expression in multiple myeloma. Leukemia 11, 1166-1169.

Damiano, J.S., Cress, A.E., Hazlehurst, L.A., et al., 1999. Cell adhesion mediated drug resistance (CAM-DR): role of integrins and resistance to apoptosis in human myeloma cell lines. Blood 93, 1658-1667.

Dao, D., Sawyer, J., Esptein, J., et al., 1994. Deletion of retinoblastoma gene in multiple myeloma. Leukemia 8, 1280-1284.

De Bruyne, E., Bos, T.J., Schuit, et al., 2010. IGF-1 suppresses Bim expression in multiple myeloma via epigenetic and posttranslational mechanisms. Blood 115, 2430-2440.

De Laeter, J.R., Böhlke, J.K., De Bievre, P., Hidaka, H., Peiser, S., Rosman, J.R., Taylor, P.D. , 2000. Atomic weights of the elements, Pure Appl Chem, 75, 800-963.

DeMichele, A., Martin, A.M., Mick, R., et al., 2003. Interleukin-6-174G $\rightarrow$ C polymorphism is associated with improved outcome in high-risk breast cancer. Cancer Res. 63, 8051-8056.

DeWald, G.W., Kyle, R.A., Hicks, G.A., Greipp, P.R., 1985. The clinical significance of cytogenetic studies in 100 patients with multiple myeloma, plasma cell leukemia, or amyloidosis. Blood 66, 380-390

Demchenko, Y.N., Glebov, O.K. Zingone, A., Keats, J.J., Bergsagel, P.L, Kuehl, W.M., 2010. Classical and/or alternative NF-kappaB pathway activation in multiple myeloma. Blood. 115 (17), 3541-3552.

Dimopoulos, M.A., Delasalle, K.B., Champlin, R., Alexanian, R., 1993. Cyclophoshamide and etoposide therapy with GM-CSF for VAD-resistant multiple myeloma. Br. J. Haematol. 83, 240-244. 
Dinarello, C.A., 2011. Interleukin-1 in the pathogenesis and treatment of inflammatory diseases. Blood 117, 3720-3732.

Durie, B.G.M., Salmon, S.E., 1975. A clinical staging system for multiple myeloma. Cancer 36, 842-854.

Durie, B.G.M., Mason, D.Y., Giles, F., et al., 1990. Expression of the bcl-2 oncogene protein in multiple myeloma. Blood 76, 347A.

Durie, B.G.M., 1992. Cellular and molecular genetic features of myeloma and related disorders. Hematol. Oncol. Clin. North Am. 6, 463-477.

Elnenaei, M.O., Gruszka-Westwood, A.M., A'Hernt, R., Matutes, E., Sirohi, B., Powles, R., Catovsky, D., 2003. Gene abnormalities in multiple myeloma; the relevance of TP53, MDM2, and CDKN2A. Haematologica 88 (5), 529-537.

Erlich, L.A., Roodman, G.D., 2005. The role of immune cells and inflammatory cytokines in Paget's disease and multiple myeloma. Immunol. Rev. 208, 252-266.

Fabre, C., Mimura, N., Bobb, K., Kong, S.Y., Gorgun, G., Cirstea, D., Hu, Y., Minami, J., Ohguchi, H., Zhang, J., Meshulam, J., Carrasco, R.D., Tai, Y.T., Richardson, P.G., Hideshima, T., Anderson, K.C., 2012. Dual inhibition of canonical and noncanonical NF-kappaB pathways demonstrates significant antitumor activities in multiple myeloma. Clin. Cancer Res. 18 (17), 4669-4681.

Facon, T., Lai, J.L., Nataf, E., et al., 1993. Improvedcytogenetic analysis of bone marrow plasma cells after cytokine stimulation in multiple myeloma: a report on 46 patients. Br. J. Haematol. 84, 743-748.

Farnebo, M., Bykov, V.J., Wiman, K.G., 2010. The p53 tumor suppressor: a master regulator of diverse cellular processes and therapeutic target in cancer. Biochem. Biophys. Res. Commun. 396, 85-89.

Fernandez, E., Gallus, S., Bosetti, C., Franceschi, S., Negri, E., La Vecchia, C., 2003. Hormone replacement therapy and cancer risk: a systematic analysis from a network of case-control studies. Int. J. Cancer 105, 408-412.

Fisher, G.A., Lum, B.L., Hausdorff, J., et al., 1996. Pharmacological considerations in the modulation of multidrug resistance. Eur. J. Cancer 32a, 1082-1088 (abstract).

Fonseca, R., Blood, E.A., Oken, M.M., et al., 2002. Myeloma and the $\mathrm{t}(11 ; 14)(\mathrm{q} 13 ; \mathrm{q} 32)$ : evidence for a biologically defined unique subset of patients. Blood 99, 3735-3741.

Fonseca, R., Blood, E., Rue, M., et al., 2003. Clinical and biologic implications of recurrent genomic aberrations in myeloma. Blood 101, 4569-4575.

Fonseca, R., Barlogie, B., Bataille, R., et al., 2004. Genetics and cytogenetics of multiple myeloma: a workshop report. Cancer Res. 64, 1546-1558.

Fonseca, R., Bergsagel, P.L., Drach, J., et al., 2009. International Myeloma Working Group. International Myeloma Working Group molecular classification of multiple myeloma: spot light review. Leukemia 23, 2210-2221.

Fotedar, R., Diederich, L., Fotedar, A., 1996. Apoptosis and the cell cycle. Prog. Cell Cycle Res. 2, 147-163

Gabrea, A., Martelli, M.L., Qi, Y., et al., 2008. Secondary genomic rearrangements involving immunoglobulin or MYC loci show similar prevalences in hyperdiploid and non-hyperdiploid myeloma tumors. Genes Chromosom. Cancer 47, 573-590.

Gaidano, G., Dalla Favera, R., 1992. Protooncogenes and tumor suppressor genes. In: Knowles, D.M. (Ed.), Neoplastic Hemopathology. Williams \& Wilkins, Baltimore, pp. 245-261.

Gazitti, Y., Liu, Q., Vesole, D., et al., 2001. Bcl-2 antisense oligonucleotide (ASO) enhances apoptosis and cytotoxicity in drug-resistant myeloma cells. Blood 98, 641a (abstract).

Gentile, M., Recchia, A.G., Mazzone, C., Lucia, E., Vigna, E., Morabito, F., 2013. Perspectives in the treatment of multiple myeloma. Expert Opin. Biol. Ther. 13 (Suppl. 1), S1-22.

Gertz, M.A., Lacy, M.Q., Dispenzieri, A., et al., 2005. Clinical implications of $\mathrm{t}(11 ; 14)(\mathrm{q} 13 ; \mathrm{q} 32), \mathrm{t}(4 ; 14)(\mathrm{p} 16 ; .3 ; \mathrm{q} 32)$, and $-17 \mathrm{p} 13$ in myeloma patients treated with high-dose therapy. Blood 106, 2837-2840.

Grepp, P.R., Durie, B.G.M., et al., 2005. International staging system fot multiple myeloma. J. Clin. Oncol. 23, 3412-3420.

Grogan, T.M., Spier, C.M., Salmon, S.E., Matzner, M., Rybski, J., Weinstein, R.S., Scheper Dalton, W.S., 1993. P-glycoprotein expression in human plasma cell myeloma: correlations with prior chemotherapy. Blood 81, 490-495.

Gupta, A.K., Gupta, M., 2005. Synthesis and surface engineering of iron oxide nanoparticles for biomedical applications. Biomaterials 26, 3995-4021.

Haimovitz-Friedman, A., Kan, C.C., Ehleiter, D., Persaud, R.S., McLoughlin, M., Fuks, Z., Kolesnick, R.N., 1994. Ionizing radiation acts on cellular membranes to generate ceramide and initiate apoptosis. J. Exp. Med. 180, 525-535

Hamilton, M.S., Barker, H.F., Ball, J., Drew, M., Abbot, S.D., Franklin, I.M., 1991. Normal and neoplastic human plasma cells express bcl-2 antigen. Leukemia 5, $768-771$.

Hawley, T.S., Riz, I., Yang, W., Wakabayashi, Y., Depalma, L., Chang, Y.T., Peng, W., Zhu, J., Hawley, R.G., 2013. Identification of an ABCB1 (P-glycoprotein)-positive carfilzomib-resistant myeloma subpopulation by the pluripotent stem cell fluorescent dye CDy1. Am. J. Hematol. 88, 265-272.

Herrmann, F., Andreeff, M., Gruss, H.J., et al., 1991. Interleukin-4 inhibits growth of multiple myelomas by suppressing interleukin-6 expression. Blood 78, 2070-2074.

Hideshima, T., Nakamura, N., Chauhan, D., Anderson, K.C., 2001. Biologic sequelae of interleukin-6 induced PI3-K/Akt signaling in multiple myeloma. Oncogene 20, 5991-6000.

Hideshima, T., Bergsagel, P.L., Kuehl, W.M., Anderson, K.C., 2004. Advances in biology of multiple myeloma: clinical applications. Blood 104, 607-618.
Hideshima, T., Mitsiades, C., Tonon, G., Richardson, P.G., Anderson, K.C., 2007. Understanding multiple myeloma pathogenesis in the bone marrow to identify new therapeutic targets. Nat. Rev. Cancer 7, 585-598.

Hokkenberry, D., Nunez, G., Milliman, C., et al., 1990. Bcl-2 is an inner mitochondrial membrane protein that blocks programmed cell death. Nature 348, 334-336.

Huang, Y.W., Hamilton, A., Arnuk, O.J., Chaftari, P., Chemoly, R., 1999. Current drug therapy for multiple myeloma. Drugs 57, 485-506.

Hulkkonen, J., Pertovaara, M., Antonen, J., Pasternack, A., Hurme, M., 2001. Elevated interleukin-6 plasma levels are regulated by the promoter region polymorphism of the IL6 gene in primary Sjögren's syndrome and correlate with the clinical manifestations of the disease. Rheumatology (Oxford) 40, 656-661.

Humphries, S.E., Luong, L.A., Ogg, E.H., Miller, G.j., 2001. The interleukin -6-174G/C promoter polymorphism is associated with risk of coronary heart disease and systolic blood pressure in healthy men. Eur. Heart J. 22, 2243-2252.

Jernberg, H., Petterson, M., Kishimoto, T., Nilsson, K., 1991. Heterogeneity in response to interleukin 6 (IL-6), expression of IL-6 and IL-6 receptor mRNA in a panel of established human multiple myeloma cell lines. Leukemia 5, 255-265.

Jerrard-Dunne, P., Sitzer, M., Risley, P., et al., 2003. Interleukin-6 promoter polymorphism modulates the effects of heavy alcohol consumption on early carotid artery atherosclerosis: the Carotid Atherosclerosis Progression Study (CAPS). Stroke 34, 402-407.

Jones, K.G., Brull, D.J., Brown, L.C., et al., 2001. Interleukin-6 (IL-6) and the prognosis of abdominal aortic aneurysms. Circulation 103, 2260-2265.

Jonsson, B., Nilsson, K., Nygren, P., Larsson, R., 1992. SDZ P50 833, a novel potent in vitro chemosensitizers in multiple myeloma. Anti-Cancer Drug 3, 641-646.

Jourdan, M., Zhang, X.G., Portier, M., et al., 1991. IFN-alpha induces an autocrine production of IL-6 in myeloma cell lines. J. Immunol. 12, 4402-4407.

Kaldis, P., Russo, A.A., Chou, H.S., Pavleitch, N.P., Solomon, M.J., 1998. Human and yeast cdk-activating kinases (CAKs) display distinct substrate specificities. Mol. Biol. Cell 9, 2545-2560.

Kapahi, P., Takahashi, T., Natoli, G., et al., 2000. Inhibition of NF-kappa-B activation by arsenite through reaction with critical cysteine in the activation loop of iota-kappa- kinase. J. Biol. Chem. 275, 36062-36066.

Kawano, M., Hirano, T., Matsuda, T., et al., 1988. Autocrine generation and requrement of BSF-2/IL-6 for human multiple myelomas. Nature 332, 83-85.

Keats, J.J., Reiman, T., Maxwell, C.A., et al., 2003. In multiple myeloma $\mathrm{t}(4 ; 14)(\mathrm{p} 16 ; \mathrm{q} 32)$ is an adverse prognostic factor irrespective of FGFR3 expression. Blood 101, 1520-1529.

Keats, J.J., Fonseca, R., Chesi, M., Schop, R., Baker, A., Chng, W.J., Van Wier, S., Tiedemann, R., Shi, C.X., Sebag, M., Braggio, E., Henry, T., Zhu, Y.X., Fogle, H. Price-Troska, T., Ahmann, G., et al., 2007. Promiscuous mutations activate the noncanonical NF-kappaB pathway in multiple myeloma. Cancer Cell. 12 (2), $131-144$.

Kishimoto, T., 1989. The biology of Interleukin-6. Blood 74, 1-10.

Klappe, K., Hinrichs, J.W., Kroesen, B.J., Sietsma, H., Kok, J.W., 2004. MRP1 and glucosylceramide are coordinately overexpressed and enriched in rafts during multidrug resistance acquisition in colon cancer cells. Int. J. Cancer 110, 511-522.

Klein, B., Zhang, X.G., Jourdan, M., et al., 1989. Paracrine rather than autocrine regulation of myeloma-cell growth and differentiation by interleukin-6. Blood 73, 517-526.

Korde, N., Kristinsson, S.Y., Landgren, O., 2011. Monoclonal gammopathy of undetermined significance (MGUS) and smoldering multiple myeloma (SMM): novel biological insights and development of early treatment strategies. Blood 117, 5573-5581.

Kuehl, W.M., Bergsagel, P.L., 2002. Multiple myeloma: evolving genetic events and host interactions. Nat. Rev Cancer 2, 175-187.

Kuhn, D.J., Berkova, Z., Jones, R.J., Woessner, R., Bjorklund, C.C., Ma, W., Davis, R.E., Lin, P., Wang, H., Madden, T.L., Wei, C., Baladandayuthapani, V., Wang, M., Thomas, S.K., Shah, J.J., Weber, D.M., et al., 2012. Targeting the insulin-like growth factor-1 receptor to overcome bortezomib resistance in preclinical models of multiple myeloma. Blood 120, 3260-3270.

Kyle, R.A., Greipp, P.R., 1980. Smoldering multiple myeloma. N. Engl. J. Med. 302. 1347-1349.

Kyle, R.A., Rajkumar, S.V., 2008. Multiple myeloma. Blood 111, 2962-2972.

Landgren, O., Gridley, G., Turesson, I., Caporaso, N.E., Goldin, L.R., Baris, D., Fears, T.R., Hoover, R.N., Linet, M.S., 2006. Risk of monoclonal gammopathy of undetermined significance (MGUS) and subsequent multiple myeloma among African American and white veterans in the United States. Blood 107, 904-906.

Le Baccon, P., Leroux, D., Dascalescu, C., et al., 2001. Novel evidence of a role for chromosome 1 pericentric heterochromatin in the pathogenesis of b-cel lymphoma and multiple myeloma. Genes Chrom. Cancer 32, 250-264.

Lee, M.-S., Blick, M.B., Pathak, S., et al., 1987. The gene located at chromosome 18 band q21 is rearranged in uncultured diffuse lymphomas as well as follicular lymphomas. Blood 70, 90-95.

Lenhard, R.E., Oken, M.M., Barnes, J.M., et al., 1984. High dose cyclophosphamide: an effective treatment for advanced myeloma. Cancer 53, 1456-1460.

Libermann, D.A., Hoffman, B., Steinman, R.A., 1995. Molecular controls of growth arrest and apoptosis: p53-dependent and independent pathways. Oncogene $11,199-210$. 
Liebmann, J., Cook, J.A., Fisher, J., Teague, D., Mitchell, J.B., 1994. In vitro studies of taxol as a radiation sensitizer in human tumor cells. J. Natl. Cancer Inst. 8, 441-446.

Lokhorts, H.M., Izquierdo, M.A.I., Raaijmakers, M.G.P., et al., 1996. Lung resistance protein expression is a negative predictive factor for response to alkylating chemotherapy and survival in multiple myeloma. Blood 88 (10), 2549.

Lonial, S., Mitsiades, C.S., Richardson, P.G., 2011. Treatment options for relapsed and refractory multiple myeloma. Clin. Cancer Res. 17 (6), 1264-1277.

Lynsenmeyer, M.E., Jefferson, S., Wof, M., et al., 1992. Levels of expression of the mdr 1 gene and glutathione-S-transferase genes 1 and 2 and response to chemotherapy in multiple myeloma. Br. J. Cancer 65, 471-475.

MacLennan, I.C.M., 1991. The origin of bone marrow plasma cells. In: Obrams, G.I. Potter, M. (Eds.), Epidemology and Biology of Multiple Myeloma. Springer-Verlag, Berlin, pp. 129-135.

Majoros, I.J., Thomas, T.P., Mehta, C.B., Baker, J.R., 2005. Poly(amidoamine) dendrimer-based multifunctional engineered nanodevice for cancer therapy. J. Med. Chem. 48, 5892-5899.

Majoros, I.J., Myc, A., Thomas, T.P., Mehta, C.B., Baker, J.R., 2006. PAMAM dendrimer-based multifunctional conjugate for cancer therapy: synthesis, characterization, and functionality. Biomacromolecules 7, 572-579.

Manier, S., Sacco, A., Leleu, X., Ghobrial, I.M., Roccaro, A.M., 2012. Bone marrow microenvironment in multiple myeloma progression. J. Biomed. Biotechnol. 2012, 157496.

Manish, G., Vimukta, S., 2011. Targeted drug delivery system: a review. Res. J. Clin. Sci. $1,135-138$

Marie, J.P., 2001. Drug resistance in hematological malignancies. Curr. Opin. Oncol. 13, 464-469

Markovina, S., Callander, N.S., O'Connor, S.L., Kim, J., Werndli, J.E., Raschko, M., Leith, C.P., Kahl, B.S., Kim, K., Miyamoto, S., 2008. Bortezomib-resistant nuclear factor-kappaB activity in multiple myeloma cells. Mol. Cancer Res. 6 (8), 1356-1364.

Matsumura, Y., Maeda, H., 1986. A new concept for macromolecular therapeutics in cancer chemotherapy: mechanism of tumoritropic accumulation of proteins and the antitumor agent SMANCS. Cancer Res. 46, 6387-6392.

Meads, M.B., Gatenby, R.A., Dalton, W.S., 2009. Environment mediated drug resistance: a major contributor to minimal residual disease. Nat. Rev. Cancer 9, 665-674.

Meltzer, P., Shadle, K., Durie, B., 1987. Somatic mutation alters a critical region of the c-myc gene in ultiple myeloma. Blood 70, 958A.

Milas, L., Hunter, N.R., Mason, K.A., Kurdoglu, B., Peters, L.J., 1994. Enhancement of tumor radioresponse of murine mammary carcinoma by paclitaxel. Cancer Res. 54, 3506-3510.

Mills, P.K., Newell, G.R., Beeson, W.L., Fraser, G.E., Philips, R.L., 1990. History of cigarette smoking and risk of leukemia and myeloma: results from the Adventist health study. J. Natl. Cancer Inst. 82, 1832-1836.

Milross, C.G., Mason, K.A., Hunter, N.R., Terry, N.H., Patel, N., Harada, S., Jibu, T., Seong, J., Milas, L., 1997. Enhanced radioresponse of paclitaxel-sensitive and -resistant tumours in vivo. Eur. J. Cancer 33, 1299-1308.

Misso, G., Zappavigna, S., Castellano, M., De Rosa, G., Di Martino, M.T., Tagliaferri, P., Tassone, P., Caraglia, M., 2013. Emerging pathways as individualized therapeutic target of multiple myeloma. Expert Opin. Biol. Ther. 13 (Suppl. 1), S95-109.

Morgan, G.J., Davies, F.E., Linet, M., 2002. Myeloma aetiology and epidemiology. Biomed. Pharmacother. 56, 223-234.

Motvani, M., Delohery, T.M., Schwartz, G.K., 1999. Sequential dependent enhancement of caspase activation and apoptosis by flavopiridol on paclitaxel-treated human gastric and breast cancer cells. Clin. Cancer Res. 5 1876-1883.

Multiple Myeloma Research Foundation. <www.themmrf.org/>.

Mundy, G.R., Raisz, L.G., Cooper, R.A., et al., 1974. Evidence for the secretion of an osteoclast stimulating factor in myeloma. N. Engl. J. Med. 291, 1041-1046.

Mutlu, P., Baran, Y., Ural, A.U., Avcu, F., Dirican, B., Beyzadeoglu, M., Gündüz, U., 2011. Effect of cobalt-60 ( $\gamma$ radiation) on multidrug-resistant multiple myeloma cell lines. Cell Biol. Int. 35, 721-725.

Mutlu, P., Ural, A.U., Gündüz, U., 2012. Differential gene expression analysis related to extracellular matrix componenets in drug-resistant RPMI-8226 cell line. Biomed. Pharmacother. 66, 228-231.

Mutlu, P., Ural, A.U., Gündüz, U., 2014. Different types of cell cycle and apoptosis related gene expressions alter in corticosteroid, vincristine and melphalan resistant U-266 multiple myeloma cell lines. Turk. J. Hematol. 31 (3), 231-238.

Nakamura, M., Merchav, S., Carter, A., et al., 1989. Expression of a novel 3. 5-kb macrophage colony-stimulating factor transcript in human myeloma cells. J. Immunol. 143, 3543-3547.

Neri, A., Murphy, J., Cro, L., et al., 1989. Ras oncogene mutation in multiple myeloma. J. Exp. Med. 170, 1715-1725.

Neri, A., Baldini, L., Trecca, D., et al., 1993. p53 gene mutation in multiple myeloma are associated with advanced forms of malignancy. Blood 81, 128-135.

Nieters, A., Deeg, E., Becker, N., 2006. Tobacco and alcohol consumption and risk of lymphoma: results of a population-based case-control study in Germany. Int. J. Cancer 118, 422-430

Nilsson, K., Jernberg, H., Pettersson, M., 1990. IL-6 as a growth factor for human multiple myeloma cells-a short overview. In: Melchers, F., Potter, M. (Eds.), Current Topics of Microbiology and Immunology, vol. 166. Springer-Verlag, Berlin, pp. 3-8.
Nishida, K., Taniwaki, M., Misawa, S., Abe, T., 1989. Nonrandom rearrangement of chromosome 14 band q32.33 in human lymphoid malignancies with mature B-cell phenotype. Cancer Res. 49, 1275-1281.

Noborio-Hatano, K., Kikuchi, J., Takatoku, M., Shimizu, R., wada, T., Ueda, M., Nobuyoshi, M., Oh, I., Sato, K., Suzuki, T., Ozaki, K., Mori, M., Nagai, T., Muroi, K., Kano, Y., Furukawa, Y., et al., 2009. Bortezomib overcomes cell-adhesion-mediated drug resistance through downregulation of VLA-4 expression in multiple myeloma. Oncogene 28, 231-242.

Nordan, R.P., Potter, M., 1986. A macrophage derived factor required by plasmacytomas for survival and proliferation in vitro. Science 233, 566-569.

Nune, S.K., Gunda, P., Thallapally, P.K., Lin, Y.Y., Forrest, M.L., Berkland, C.J., 2009. Nanoparticles for biomedical imaging. Expert Opin. Drug Deliv. 6, 1175-1194

O’Connor, R., Ooi, M.G., Meiller, J., Jakubikova, J., Klippel, S., Delmore, J., Richardson, P., Anderson, K., Clynes, M., Mitsiades, C.S., O'Gorman, P., 2013. The interaction of bortezomib with multidrug transporters: implications for therapeutic applications in advanced multiple myeloma and other neoplasias. Cancer Chemother. Pharmacol. 71, 1357-1368.

Oken, M.M., 1984. Multiple myeloma. Med. Clin. North Am. 68, 757-787.

Palumbo, A.P., Pileri, A., Dianzani, U., et al., 1989. Altered expression of growth-regulated proto-oncogenes in human malignant plasma cells. Cancer Res. 49, 4701-4704.

Palumbo, A.P., Boccadoro, M., Battaglio, S., Corradini, P., Tsichlis, P.N., Huebner, K., Pileri, A., Croce, C.M., 1990. Human homologue of Moloney leukemia virus integration-4 locus (MLVI-4), located 20 kilobases 3' of the MYC gene, is rearranged in multiple myelomas. Cancer Res. 50, 6478-6482.

Palunbo, A., Anderson, L., 2011. Multiple myeloma. N. Engl. J. Med. 364, 1046-1060.

Pan, S.Y., Johnson, K.C., Ugnat, A.M., Wen, S.W., Mao, Y., 2004. Association of obesity and cancer risk in Canada. Am. J. Epidemol. 159, 259-268.

Paquette, R.L., Berenson, J., Lichtenstein, A., McCormick, F., Koeffler, H.P., 1990. Oncogenes in multiple myeloma: apoint mutation of N-ras. Oncogene 5 , 1659-1663.

Parkin, D.M., Whelan, S.L., Ferlay, J., Teppo, L., Thomas, D.B., 2002. Cancer in Five Continents, Vol. VIII. IARC, Lyon, IARC Scientific Publication No. 155

Piette, J., Neel, H., Marechal, V., 1997. Mdm2: keeping p53 under control. Oncogene $15,1001-1010$.

Pollak, M., 2008. Insulin and insulin-like growth factor signalling in neoplasia. Nat. Rev. Cancer 8, 915-928.

Portier, M., Molés, J.P., Mazars, G.R., et al., 1992. p53 and ras gene mutations in multiple myeloma. Oncogene 7, 2532-2543.

Portier, M., Zhang, X.G., Caron, E., et al., 1993. Gamma interferon in multiple myeloma: inhibition of interleukin-6 (IL-6)-dependent myeloma cell growth and downregulation of IL-6 receptor expression in vitro. Blood 81, 3076-3082.

Qazilbash, M.H., Saliba, R.M., Ahmed, B., et al., 2007. Deletion of the short arm of chromosome 1(del1p) is a strong predictor of poor outcome in myeloma patients undergoing an autotransplant. Biol. Blood Marrow Transpl. 13, 1066-1072.

Raaijmakers, M.H., 2007. ATP-binding-cassette transporters in hematopoietic stem cells and their utility as therapeutical targets in acute and chronic myeloid leukemia. Leukemia 21, 2094-2102.

Raffeld, M., Jaffe, E.S., 1991. Bcl-1 t(11;14), and mantle cell-derived lymphomas. Blood 78, 259-263.

Rayburn, E., Zhang, R., He, J., Wang, H., 2005. MDM2 and human malignancies: expression, clinical pathology, prognostic markers, and implications for chemotherapy. Curr. Cancer Drug Targets 5 (1), 27-41.

Ries, L.A.G., Eisner, M.P., Kosary, C.L., Hankey, B.F., Miller, B.A., Clegg, L., Mariotto, A. Feuer, E.J., Edwards, B.K. (Eds.), 2005. National Cancer Institute, Bethesda, MD.

Roodman, G.D., 2009. Pathogenesis of myeloma bone disease. Leukemia 23, $435-441$.

Ross Garrett, I., Durie, B.G.M., Nedwin, G.E., et al., 1987. Production of lymphotoxin, a bone-resorbing cytokine, by cultured human myeloma cells. N. Engl. J. Med. 317, 526-532

Ross, D.D., Yang, W., Abruzzo, L.V., et al., 1999. Atypical multidrug resistance: breast cancer resistance protein messenger RNA expression in mitoxantrone-selected cell lines. J. Natl. Cancer Inst. 91, 429-433.

Saha, M.N., Qiu, L., Chang, H., 2013. Targeting p53 by small molecules in hematological malignancies. J. Hematol. Oncol. 6, 23.

Santra, M., Zhan, F., Tian, E., et al., 2003. A subset of multiple myeloma harboring the $t(4 ; 14)(p 16 ; q 32)$ translocation lacks FGFR3 expression but maintains an IGH/MMSET fusion transcript. Blood 101, 2374-2376.

Sawczenko, A., Azooz, O., Paraszczuk, J., et al., 2005. Intestinal inflammation-induced growth retardation acts through IL-6 in rats and depends on the $-174 \mathrm{G} / \mathrm{C}$ polymorphism in children. Proc. Natl. Acad. Sci. U. S. A. $102,13260-13265$.

Sawyer, J.R., Waldron, J.A., Jagannath, S., Barlogie, B., 1995. Cytogenetic findings in 200 patients with multiple myeloma. Cancer Genet. Cytogenet. 82, 41-49.

Schmidmaier, R., Baumann, P., Simsek, M., Dayyani, F., Emmerich, B., Meinhardt, G., 2004. The HMG-CoA reductase inhibitor simvastatin overcomes cell adhesion-mediated drug resistance in multiple myeloma by geranylgeranylation of Rho protein and activation of Rho kinase. Blood 104 1825-1832.

Selvanaygam, P., Blick, M., Narni, F., et al., 1988. Alteration and abnormal expression of the c-myc oncogene in human multiple myeloma. Blood 71 , 30-35.

Sfrent-Cornateanu, R., Mihai, C., Balan, S., Ionescu, R., Moldoveanu, E., 2006. The IL-6 promoter polymorphism is associated with disease activity and disability in systemic sclerosis. J. Cell. Mol. Med. 10, 955-959. 
Sikic, B.I., 1993. Modulation of multidrug resistance: at the threshold. J. Clin. Oncol. $11,1629-1635$.

Singh, J., Dudley Jr., A.W., Kulig, K.A., 1990. Increased incidence of monoclonal gammopathy of undetermined significance in blacks and its age-related differences with ehites on the basis of a study of 397 men and one woman in a hospital setting. J. Lab. Clin. Med. 116, 789-7858.

Smadja, N.V., Louvet, C., Isnard, F., et al., 1995. Cytogenetic study in multiple myeloma at diagnosis: comparison of two techniques. Br. J. Haematol. 90, 619-624.

Smadja, N.V., Fruchart, C., Isnard, F., et al., 1998. Chromosomal analysis in mltiple myeloma: cytogenetic evidence of two different diseases. Leukemia 12 960-969.

Smadja, N.V., Bastard, C., Brigaudeau, C., et al., 2001. Hypodiploidy is a major prognostic factor in multiple myeloma. Blood 98, 2229-2238.

Smith, A.J., Dai, H., Correia, C., Takahashi, R., Lee, S.H., Schmitz, I., Kaufmann, S.H., 2011. Noxa/Bcl-2 protein interactions contribute to bortezomib resistance in human lymphoid cells. J. Biol. Chem. 286, 17682-17692.

Snoussi, K., Strosberg, A.D., Bouaouina, N., Ahmed, S.B., Chouchane, L., 2005. Genetic variation in pro-inflammatory cytokines (interleukin- $1 \beta$, interleukin-1 $\alpha$ and interleukin-6) associated with the aggressive forms, survival and relapse prediction of breast carcinoma. Eur. Cytokine Netw. 16, 253-260.

Sonneveld, P., Dune, B.G.M., Lokhorst, H.M., Marie, J.P., Solbu, G., Suciu, S., Zittoun, R., Lowenberg, B., Nooter, K., 1992a. Modulation of multidrug resistant multiple myeloma by cyclosporine. Lancet 340, 255-259.

Sonneveld, P., Marier, J.P., Huisman, C., et al., 1992b. Modulation of multidrug resistant multiple myeloma by cyclosporin. Lancet 340, 255-259.

Sun, C., Lee, J.S.H., Zhang, M.Q., 2008. Magnetic nanoparticles in MR imaging and drug delivery. Adv. Drug Deliv. Rev. 60, 1252-1265.

Supiot, S., Thillays, F., Rio, E., Gouard, S., Morgenstern, A., Bruchertseifer, F., Mahé, M.A., Chatal, J.F., Davodeau, F., Chérel, M., 2007. Gemcitabine radiosensitizes multiple myeloma cells to low let, but not high let, irradiation. Radiother. Oncol. 83, 97-101.

Tan, D.S., Gerlinger, M., Teh, B.T., Swanton, C., 2010. Anti-cancer drug resistance: understanding the mechanisms through the use of integrative genomics and functional RNA interference. Eur. J. Cancer 46, 2166-2177.

Tang, J.L., Yeh, S.H., Chen, P.J., 1992. Inactivation of the retinoblastoma gene in acute myelogenous leukemia. Br. J. Haematol. 82, 502-507.

Thorburn, et al., 2014. Autophagy controls the kinetics and extent of mitochondrial apoptosis by regulating PUMA levels. Cell Rep. 7 (1), 45-52.

Tian, E., Zhan, F., Walker, R., et al., 2003. The role of the Wnt-signaling antagonist DKK1 in the development of osteolytic lesions in multiple myeloma. N. Engl. J. Med. 349, 2483-2494.

Tricot, G., Barlogie, B., Jagannath, S., et al., 1995. Poor prognosis in multiple myeloma is associated only with partial or complete deletions of chromosome 13 or abnormalities involving $11 \mathrm{q}$ and not with other karyotype abnormalities. Blood 86, 4250-4256.

Tricot, G., Sawyer, J.R., Jagannath, S., et al., 1997. Unique role of cytogenetics in the prognosis of patients with myeloma receiving high-dose therapy and autotransplants. J. Clin. Oncol. 15, 2659-2666.

Turner, J.G., Gump, J.L., Zhang, C., Cook, J.M., Marchion, D., Hazlehurst, L., Munster, P., Schell, M.J., Dalton, W.S., Sullivan, D.M., 2006. ABCG2 expression, function and promoter methylation in human multiple myeloma. Blood 108, 3881-3889.

Ueda, K., Cardarelli, C., Gottesman, M.M., Pastan, I., 1987. Expression of a full-lenght cDNA for the human MDR1 gene confers resistance to cochicine, doxorubicin and vinblastine. Proc. Natl. Acad. Sci. U. S. A. 84, 3004-3008.

Van Hoeven, K.H., Reed, L.J., Factor, S.M., 1990. Autopsy documented cure of multiple myeloma 14 years after M2 chemotherapy. Cancer 60, 1472-1474

Vlajinac, H.D., Pekmezovic, T.D., Adanja, B.J., Marinkovic, J.M., Kanazir, M.S. Suvajdzic, N.D., Colovic, M.D., 2003. Case-control study of multiple myeloma with special reference to diet as risk factor. Neoplasma 50, 79-83.

Wang, S., La, J., 2013. The resistance mechanisms of proteasome inhibitor bortezomib. Biomark. Res. 1, 1-9.

Weiss, B.M., Abadie, J., Verma, P., Howard, R.S., Kuehl, W.M., 2009. A monoclonal gammopathy precedes multiple myeloma in most patients. Blood 113, 5418-5422.
Williams, M.E., Meecker, T.C., Swerdlow, S.H., 1991. Rearrangement of the chromosome 11 bcl-1 locus in centrocytic lymphoma: analysis with multiple breakpoint probes. Blood 78, 493-498.

Wuchter, C., Karawajew, L., Ruppert, V., et al., 1999. Clinical significance of CD95, $\mathrm{Bcl}-2$ and Bax expression and CD95 function in adult de novo acute myeloid leukemia in context of P-glycoprotein function, mutation stage, and cytogenetics. Leukemia 13, 1943-1953.

Xiang, Y., Remily-Wood, E.R., Oliveira, V., Yarde, D., He, L., Cheng, J.Q., Mathews, L., Boucher, K., Cubitt, C., Perez, L., Gauthier, T.J., Eschrich, S.A., Shain, K.H., Dalton, W.S., Hazlehurst, L., Koomen, J.M., 2011. Monitoring a nuclear factor-kappaB signature of drug resistance in multiple myeloma. Mol. Cell. Proteomics 10 (11), M110005520.

Yaccoby, S., Ling, W., Zhan, F., Walker, R., Barlogie, B., Shaugnessy Jr., J.D., 2007. Antibody-based inhibition of DKK1 suppresses tumor-induced bone resorption and multiple myeloma growth in vivo. Blood 109, 2106-2111.

Yang, H.H., Ma, M.H., Vescio, R.A., Berenson, J.R., 2003. Overcoming drug resistance in multiple myeloma: the emergence of therapeutic approaches to induce apoptosis. J. Clin. Oncol. 21, 4239-4247.

Yang, Q., Zhang, J., Wang, S.M., Zhang, J.R., 2004. Expression of glycosylceramide synthase mRNA in vincristine-resistant KBV200 cell line in association with multidrug resistance. Di Yi Jun Yi Da Xue Xue Bao 24, 779-781.

Zhang, X.C.G., Klein, B., Bataille, R., 1989. Interleukin-6 is a potent myeloma-cell growth factor in patients with aggressive multiple myeloma. Blood 74, 11-13.

Zhang, X.G., Bataille, R., Jourdan, M., et al., 1990. Granulocyte-macrophage colony stimulating factor synergizes with interleukin-6 in supporting the proliferation of human myeloma cells. Blood 76, 2599-2605.

Zhang, X.G., Bataille, R., Wijdenes, J., Klein, B., 1992. Interleukin-6 dependence of advanced malignant plasma cell dyscrasias. Cancer 69, 1373-1376.

Zojer, N., et al., 2001. Deletion of 13q14 remains an independent prognostic variable in multiple myeloma despite its frequent detection by interphase flourescence in situ hybridization. Blood 95, 1925-1930.

\section{Biographies}

Pelin Mutlu is a researcher in Central Laboratory Molecular Biology and Biotechnology R\&D Center at Middle East Technical University. She is responsible from Genome Analysis Laboratory which is one of the laboratory in Central Laboratory. Dr. Mutlu, graduated from Middle East Technical University, Biological Sciences Department and got her PhD degree in the same department. Her research interests are cancer molecular biology, drug resistance and anti-cancer drug targeting by polymeric magnetic nanoparticles.

Prof. Dr. Ufuk Gündüz is professor of Molecular Biology and Genetics in Middle East Technical University, Biological Sciences Department, Ankara. She is graduated from lowa State University (USA), then received her PhD in Middle East Technical University. Her research interests are cancer molecular biology, drug resistance, and anti-cancer drug targeting by polymeric nanoparticles. Another line of research of Dr. Gündüz is related to Biohydrogen production by photosynthetic bacteria.

Yusuf Baran is a professor in the Department of Molecular Biology and Genetics, at Abdullah Gul University. His career in cancer research began at Middle East Technical University (METU), which is renowned in the area of molecular biology. Understanding cell death mechanisms in cancer was the aim of his masters and doctoral education, which was completed at METU. During his doctoral work, he worked in the Medical University of South Carolina, Holling Cancer Center, USA Thereafter, he joined the Department of Molecular Biology and Genetics at Izmir Institute of Technology where he became a professor. He established the "Cancer Genetics Research Laboratory" in this university. Dr. Baran is an currently working as a dean and full-time professor at Abdullah Gul University, Faculty of Life and Natural Sciences. 